\title{
Assessment of Betulinic Acid Cytotoxicity and Mitochondrial Metabolism Impairment in a Human Melanoma Cell Line
}

\author{
Dorina Coricovac $1,2,+\oplus$, Cristina Adriana Dehelean $1,2,+$, Iulia Pinzaru $1,2, * \mathbb{1}$, Alexandra Mioc $1,2, *$, \\ Oana-Maria Aburel ${ }^{3,4}$, Ioana Macasoi ${ }^{1,2}$, George Andrei Draghici ${ }^{1,2}{ }^{1}$, Crina Petean ${ }^{1}$, Codruta Soica ${ }^{1,2}$, \\ Madalina Boruga ${ }^{3}$, Brigitha Vlaicu ${ }^{3}$ and Mirela Danina Muntean ${ }^{3,4}$ \\ 1 Faculty of Pharmacy, "Victor Babeș" University of Medicine and Pharmacy Timișoara, \\ Eftimie Murgu Square No. 2, RO-300041 Timișoara, Romania; dorinacoricovac@umft.ro (D.C.); \\ cadehelean@umft.ro (C.A.D.); macasoi.ioana@umft.ro (I.M.); draghici.george-andrei@umft.ro (G.A.D.); \\ crina.petean@umft.ro (C.P.); codrutasoica@umft.ro (C.S.) \\ 2 Research Center for Pharmaco-toxicological Evaluations, Faculty of Pharmacy, "Victor Babes" University of \\ Medicine and Pharmacy Timișoara, Eftimie Murgu Square No. 2, RO-300041 Timișoara, Romania \\ 3 Faculty of Medicine "Victor Babeș" University of Medicine and Pharmacy Timișoara, \\ Eftimie Murgu Square No. 2, RO-300041 Timișoara, Romania; oanaduicu@umft.ro (O.-M.A.); \\ madalina.boruga@umft.ro (M.B.); vlaicu@umft.ro (B.V.); daninamuntean@umft.ro (M.D.M.) \\ 4 Center for Translational Research and Systems Medicine, Faculty of Medicine," Victor Babeș" University of \\ Medicine and Pharmacy Timișoara, Eftimie Murgu Sq. no. 2, RO-300041 Timișoara, Romania \\ * Correspondence: iuliapinzaru@umft.ro (I.P.); alexandra.petrus@umft.ro (A.M.); Tel.: +40-256-494-604 \\ + Authors with equal contribution.
}

Citation: Coricovac, D.; Dehelean, C.A.; Pinzaru, I.; Mioc, A.; Aburel, O.-M.; Macasoi, I.; Draghici, G.A.; Petean, C.; Soica, C.; Boruga, M.; et al. Assessment of Betulinic Acid Cytotoxicity and Mitochondrial Metabolism Impairment in a Human Melanoma Cell Line. Int. J. Mol. Sci. 2021, 22, 4870. https://doi.org/ $10.3390 /$ ijms 22094870

Academic Editors: Patrizia Bottoni and Alvaro Mordente

Received: 19 March 2021

Accepted: 1 May 2021

Published: 4 May 2021

Publisher's Note: MDPI stays neutral with regard to jurisdictional claims in published maps and institutional affiliations.

Copyright: (c) 2021 by the authors. Licensee MDPI, Basel, Switzerland. This article is an open access article distributed under the terms and conditions of the Creative Commons Attribution (CC BY) license (https:/ / creativecommons.org/licenses/by/ $4.0 /)$.
Abstract: Melanoma represents one of the most aggressive and drug resistant skin cancers with poor prognosis in its advanced stages. Despite the increasing number of targeted therapies, novel approaches are needed to counteract both therapeutic resistance and the side effects of classic therapy. Betulinic acid (BA) is a bioactive phytocompound that has been reported to induce apoptosis in several types of cancers including melanomas; however, its effects on mitochondrial bioenergetics are less investigated. The present study performed in A375 human melanoma cells was aimed to characterize the effects of BA on mitochondrial bioenergetics and cellular behavior. BA demonstrated a dose-dependent inhibitory effect in both mitochondrial respiration and glycolysis in A375 melanoma cells and at sub-toxic concentrations $(10 \mu \mathrm{M})$ induced mitochondrial dysfunction by eliciting a decrease in the mitochondrial membrane potential and changes in mitochondria morphology and localization. In addition, BA triggered a dose-dependent cytotoxic effect characterized by apoptotic features: morphological alterations (nuclear fragmentation, apoptotic bodies) and the upregulation of pro-apoptotic markers mRNA expression (Bax, Bad and Bak). BA represents a viable therapeutic option via a complex modulatory effect on mitochondrial metabolism that might be useful in advanced melanoma or as reliable strategy to counteract resistance to standard therapy.

Keywords: betulinic acid; melanoma; mitochondria; OXPHOS; glycolysis; apoptotic markers; mitochondrial membrane potential

\section{Introduction}

Cutaneous malignant melanoma, the most fatal form of skin cancer, is portrayed as a heterogeneous disorder based on distinct genomes, transcriptomes, proteomes, and epigenomes found within a tumor and, also, the presence of cellular plasticity, features that proved to be real-challenging for the novel therapeutic agents [1-3]. According to the European Cancer Information System (ECIS) rapport, in 2020, the estimated incidence of melanoma new cases was of approximative 210,000, the highest rates being reported for Northern European countries (Denmark and Sweden-50 to 42.1: 100,000 people) and Netherlands (48.5: 100,000), whereas the lowest numbers were accounted in the SouthEastern European countries (Bulgaria and Romania-9.0 and 7.9, respectively) [4]. A major 
concern regarding melanoma is represented by the advanced metastatic tumors that are unresectable and become very rapidly resistant to treatment (after several months only) due to the multiple mutations acquired that impact on proliferation, survival, and metastasis [2] Despite the current available therapies and the progress recorded in melanoma treatment and diagnostic tools (targeted therapies for BRAF-mutated melanomas-vemurafenib, dabrafenib; immunotherapy—ipilimumab, nivolumab, pembrolizumab; and combined therapies), invasive melanoma remains the primary cause of skin cancer deaths and a continuous increment of melanoma incidence was recorded worldwide, even though the mortality rates decreased in the latest years [5]. All these facts suggest an urgent need for improvement of existing methods for melanoma prevention and protection, as well as to discover new diagnostic markers and innovative therapies that will bypass the resistance of melanoma cells and reduce the side effects of current therapies [6]. An innovative and feasible strategy for melanoma treatment consists in understanding the tumor cellular energetic metabolism, mainly the role of mitochondria in melanoma, a topic of great interest in recent years.

Mitochondria are versatile organelles that exert multiple functions within mammalian cells, as: (i) suppliers of cellular ATP (adenosine triphosphate) by oxidative phosphorylation, (ii) modulators of $\mathrm{Ca}^{2+}$ homeostasis, (iii) regulators of apoptosis via the intrinsic pathway, and iv) a source of reactive oxygen species (ROS) with both modulator and deleterious roles [7]. According to recent evidence, mitochondrial metabolism was upgraded from a simple bystander in the oncogenic process to a fundamental player in all the phases of the tumoral process including malignant transformation, tumor progression, and treatment efficiency [8]. The implication of mitochondria in melanoma development resides in the metabolic plasticity displayed by melanoma cells in the presence of different activators (AKT (protein kinase B), BRAF (v-raf murine sarcoma viral oncogene homolog B1), p14ARF, MYC, NRAS (neuroblastoma RAS viral oncogene homolog), phosphatidylinositol4,5- bisphosphate 3 kinase catalytic subunit a (PIK3CA), and phosphatase and tensin homolog (PTEN)) [9], as follows: (i) BRAF-mutant melanomas exhibit a glycolytic phenotype that switches to oxidative phosphorylation (OXPHOS) in the presence of BRAF inhibitors; (ii) NRAS-mutant melanomas rely on aerobic glycolysis, and (iii) melanomas expressing peroxisome proliferator-activated receptor $\gamma$, coactivator $1 \alpha$ (PGC- $1 \alpha$ ) or PTEN present enhanced OXPHOS associated with a reduced glycolytic profile [6,10-12]. Moreover, melanoma cells proved to be highly adaptable in a metabolic manner, in response to different environmental conditions, as hypoxia or low extracellular glucose. Taken together, these findings underline the dynamic function of mitochondria in melanoma growth/progression/survival, treatment responses and resistance development $[6,7,13]$ and the urge to get a more detailed picture of melanoma cells altered energy metabolism to overcome the drawbacks.

Agents that target mitochondria or interfere with mitochondria bioenergetics could be considered an alternative therapy that in combination with the current antimelanoma treatments augment the chemotherapeutics efficacy and delays the occurrence of resistance. A compound that complies with these requirements is betulinic acid (BA). The pentacyclic lupane-type triterpenoid, betulinic acid (3ß-hydroxy-lup-20(29)-en-28-oic acid), exerts an extensive pharmacological profile that comprises: anticancer, anti-inflammatory, anti-bacterial, anti-HIV, anti-helminthic, and antiangiogenic effects. In addition, BA also exhibits anti-diabetic, anti-dyslipidemic, and other effects as summarized in three excellent reviews [14-16]. The features that make BA a very attractive compound for researchers in the field of carcinogenesis are the high toxicity for cancer cells and the very low toxicity on normal cells (as demonstrated in vitro on dermal fibroblasts and peripheral blood lymphocytes and in vivo on normal cells/organs at relatively high therapeutic doses, respectively) [17].

Studies performed over the past decade stated that BA inhibits the growth and induces apoptosis in multiple human cancer cell lines, several mechanisms being reported here: (i) the induction of apoptosis in a caspases activation dependent manner, correlated with 
an upregulation of the pro-apoptotic proteins of Bcl-2 (B-cell lymphoma 2) family, Bax and Bcl-xs [18]; (ii) the activation of p38 and SAP/JNK (pro-apoptotic MAPK subgroups), with the involvement of ROS upstream of MAPK response [19], and (iii) the induction of ROS generation [14]. Elucidation of the BA's antimelanoma mechanisms of action is far from being complete. Although its mitochondrial-dependent proapoptotic effect has been described, information regarding the modulation of mitochondrial bioenergetics is rather scarce.

This present work is intended to comprehensively characterize the effects of BA on mitochondrial bioenergetics and cellular behavior in A375 human melanoma cells.

\section{Results}

\subsection{High Concentrations of BA Promote Cytotoxicity and Morphological Changes in HaCaT Cells}

The findings of previous studies regarding the lack of toxicity induced by BA treatment in normal cells [20-22] are debatable. On this line, we verified the impact of BA treatment for $24 \mathrm{~h}$ on $\mathrm{HaCaT}$ (human immortalized) healthy cells' viability by employing the MTT assay. Incubation of $\mathrm{HaCaT}$ cells with different concentrations of BA led to the following results: the lowest concentrations tested $(1,5$ and $10 \mu \mathrm{M})$ did not affect cells viability, whereas higher doses $(20,25$ and $50 \mu \mathrm{M})$ induced a dose-dependent decrease of cells viability, the percentage of viable cells calculated at the highest concentration tested$50 \mu \mathrm{M}$ was $81.42 \%$ (see Figure 1). The results were normalized to DMSO, the solvent that was used to solubilize BA.

\section{HaCaT - immortalized human keratinocytes - 24 h}

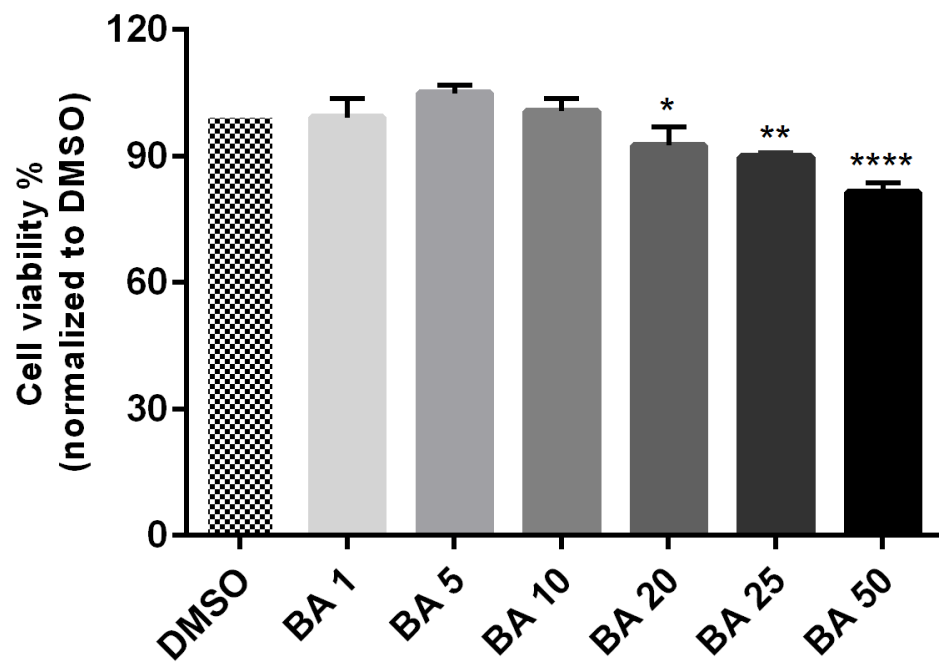

Figure 1. In vitro viability evaluation of $\mathrm{BA}(1,5,10,20,25$ and $50 \mu \mathrm{M})$ in HaCaT cells at $24 \mathrm{~h}$ post-stimulation by MTT assay. The results are expressed as cell viability percentage (\%) normalized to control (DMSO-stimulated) cells. The data represent the mean values $\pm \mathrm{SD}$ of three independent experiments performed in triplicate. One-way ANOVA analysis was applied to determine the statistical differences in rapport with DMSO followed by Dunnett's multiple comparisons post-test $\left({ }^{*} p<0.05,{ }^{* *} p<0.01\right.$ and $\left.{ }^{* * *} p<0.0001\right)$.

Another morphological hallmark for the cytotoxicity of a compound, is represented by the nuclear changes that indicate the presence of apoptotic or necrotic cells. To verify the type of cell death induced by BA $(10,20$ and $50 \mu \mathrm{M}-$ the concentrations were selected based on the cell viability results) in $\mathrm{HaCaT}$ cells, the nuclei were stained using Hoechst 33342 dye (Figure 2). As positive control for apoptosis induction was used Staurosporine solution $(5 \mu \mathrm{M})$, and for necrosis-Triton X-100 solution $(0.5 \%)$. Signs of apoptosis, as nuclear shrinkage or nuclear fragmentation (yellow arrows) were observed only in HaCaT cells treated with the highest concentrations of BA-20 and $50 \mu \mathrm{M}$, whereas BA $10 \mu \mathrm{M}$ had no 
impact on $\mathrm{HaCaT}$ cells nuclei-the nuclei presented a round shape and no sign of chromatin condensation or blebbing, their aspect being similar with the one presented by the control cells and DMSO. No signs of necrosis (red arrow) were detected in HaCaT cells treated with BA or DMSO (Figure 2). Taken together, these results indicate that low concentrations of BA $(1-10 \mu \mathrm{M})$ have no impact on $\mathrm{HaCaT}$ cells viability and morphology, whereas higher concentrations $(20,25$, and $50 \mu \mathrm{M})$ reduce cells viability and induce morphological alterations (loss of contact with neighboring cells, cells shrinkage, nuclear fragmentation) specific for apoptotic death.

HaCaT - immortalized human keratinocytes - $24 \mathrm{~h}$
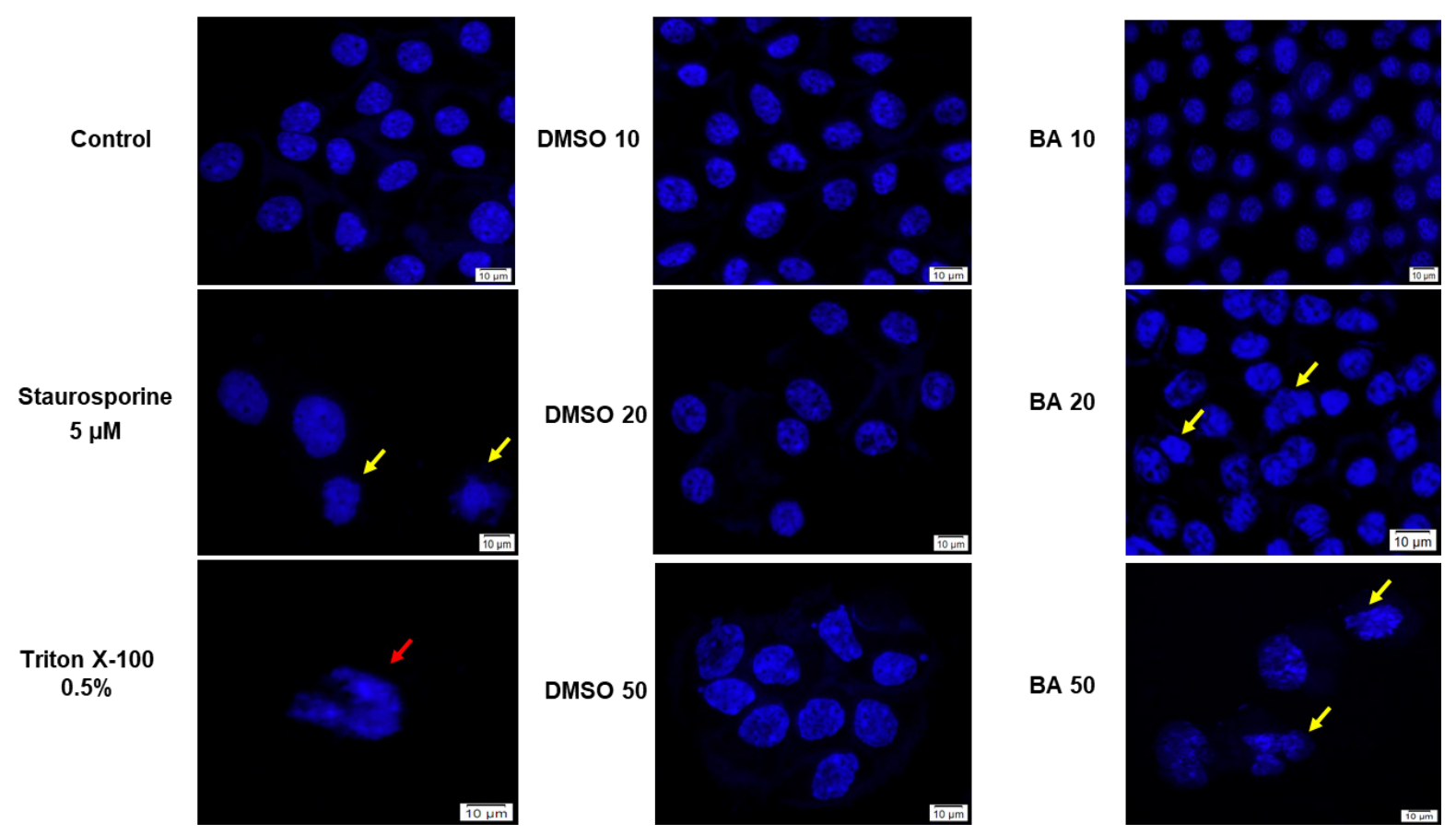

Figure 2. Cell nuclei staining using Hoechst 33342 in HaCaT cells after treatment with BA (10, 20 and $50 \mu \mathrm{M})$ and DMSO for $24 \mathrm{~h}$. The pictures were taken at $24 \mathrm{~h}$ post-treatment. Staurosporine solution $(5 \mu \mathrm{M})$ represents the positive control for apoptotic changes at nuclear level and Triton X-100 solution ( $0.5 \%)$ for necrosis. The yellow arrows represent signs of apoptosis as nuclear shrinkage or nuclear fragmentation, and the red arrow indicates signs of necrosis as cellular membrane disruption. The scale bar was $10 \mu \mathrm{m}$.

\subsection{BA Exerts a Dose-Dependent Cytotoxic Effect in A375 Human Melanoma Cells}

To decipher the BA antimelanoma mechanism of action, we selected as experimental model the A375 - human melanoma cell line. Compared to control group (DMSO-treated cells) BA treatment $(24 \mathrm{~h})$ determined a dose-dependent reduction in cell viability percentage (Figure 3). The decrease of cells' viability percentage was observed starting at $10 \mu \mathrm{M}$ $(91.39 \%)$, but the lowest percentage of viable cells was recorded at the highest concentration tested-50 $\mu \mathrm{M}(68.22 \%)$. The calculated $\mathrm{IC}_{50}$ was $16.91 \mu \mathrm{M}$.

Since BA treatment exerted a dose-dependent cytotoxic effect in A375 cells, we also verified its impact in terms of morphological alterations (Figure 4). The presence of several roundish and detached cells, but unmodified adherence and cell-cell contact was noticed at $10 \mu \mathrm{M}$ BA concentration as compared to control cells (untreated cells). The highest BA concentration tested $-50 \mu \mathrm{M}$ induced significant morphological changes characterized by the presence of round cells floating, loss of cell-cell adhesions, loss of adherence, reduced confluence, and cellular debris (Figure 4), clear signs of cytotoxicity. 


\section{A375 - human melanoma cells - $24 \mathrm{~h}$}

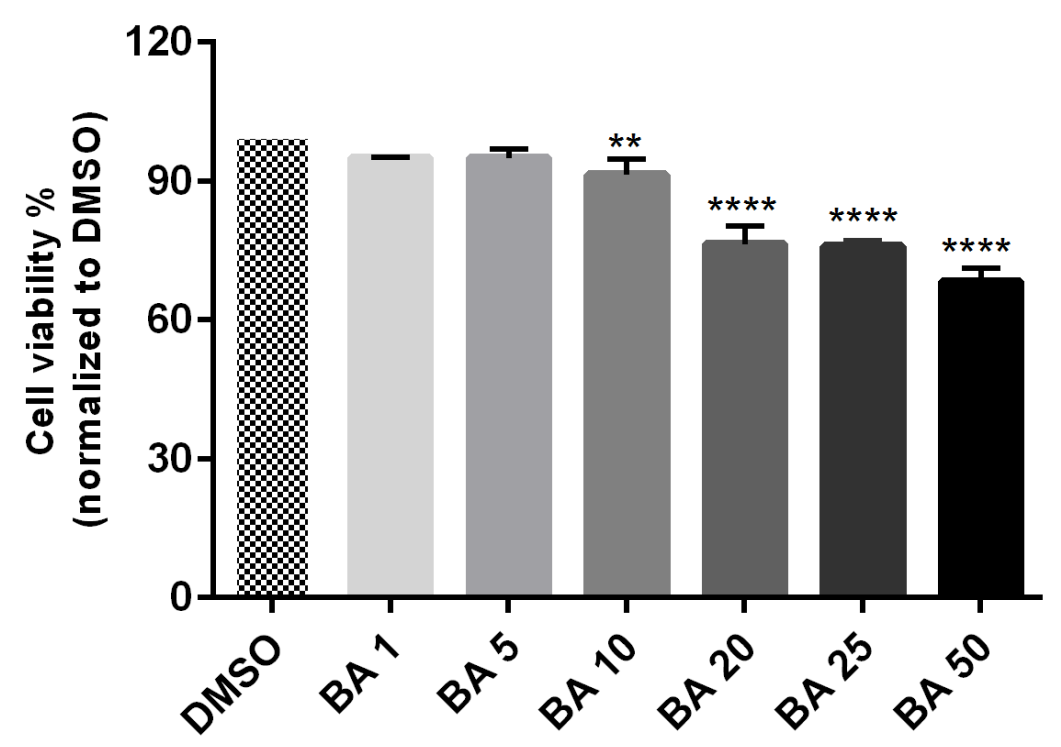

Figure 3. In vitro viability evaluation of $\mathrm{BA}(1,5,10,20,25$ and $50 \mu \mathrm{M})$ in A375 cells at 24 h poststimulation by MTT assay. The results are expressed as cell viability percentage (\%) normalized to control (DMSO-stimulated) cells. The data represent the mean values \pm SD of three independent experiments performed in triplicate. One-way ANOVA analysis was applied to determine the statistical differences in rapport with DMSO followed by Dunnett's multiple comparisons post-test (** $p<0.01$ and $\left.^{* * * *} p<0.0001\right)$.

A375 - human melanoma cells $-24 \mathrm{~h}$

Control

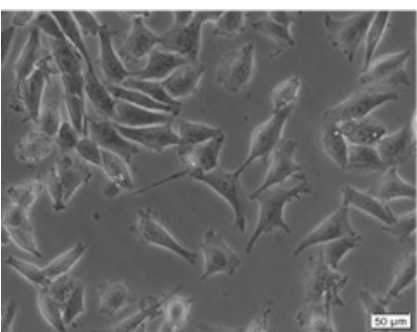

DMSO 5
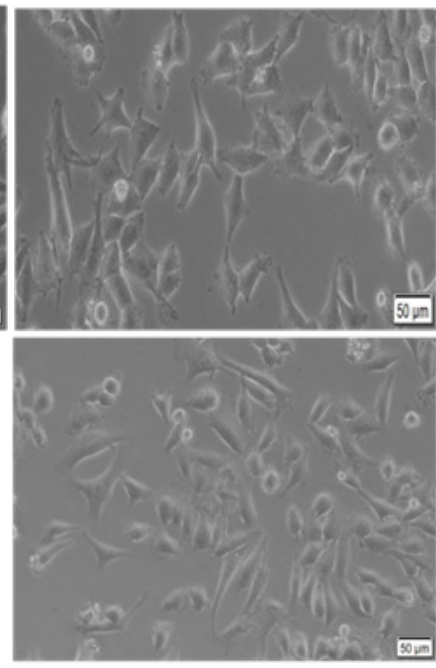

BA 5
DMSO 10
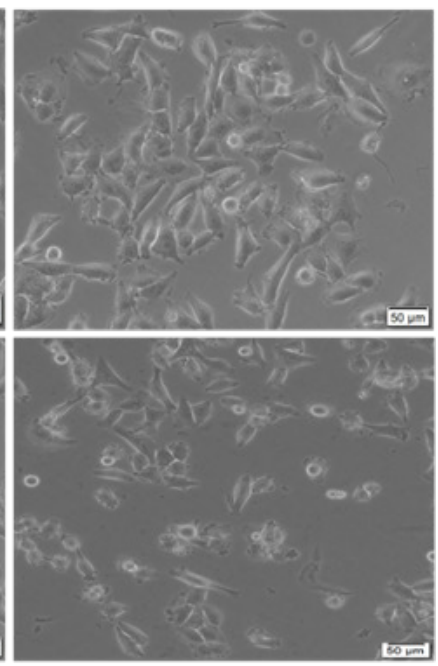

BA 10
DMSO 50
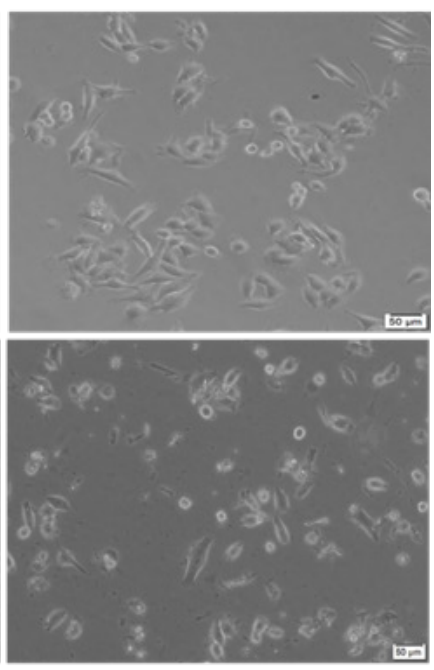

BA 50

Figure 4. Representative images of the morphological aspect of A375 cells after treatment for $24 \mathrm{~h}$ with BA and DMSO (5, 10 and $50 \mu \mathrm{M})$. The scale bar was $50 \mu \mathrm{m}$.

No morphological changes were detected in the DMSO-treated cells (solvent used for BA solubilization), their morphology and shape being similar to that of control cells (untreated): adherent and confluent cells, with an epithelial morphology (Figure 4). 
The pictures presented in Figure 4 were selected as representative concentrations to clearly observe the changes that took place in melanoma cells morphology after BA treatment.

To clearly delineate the type of cell death triggered by BA treatment, we decided to perform nuclear staining using Hoechst 33342 dye (Figure 5).

A375 - human melanoma cells $-24 \mathrm{~h}$

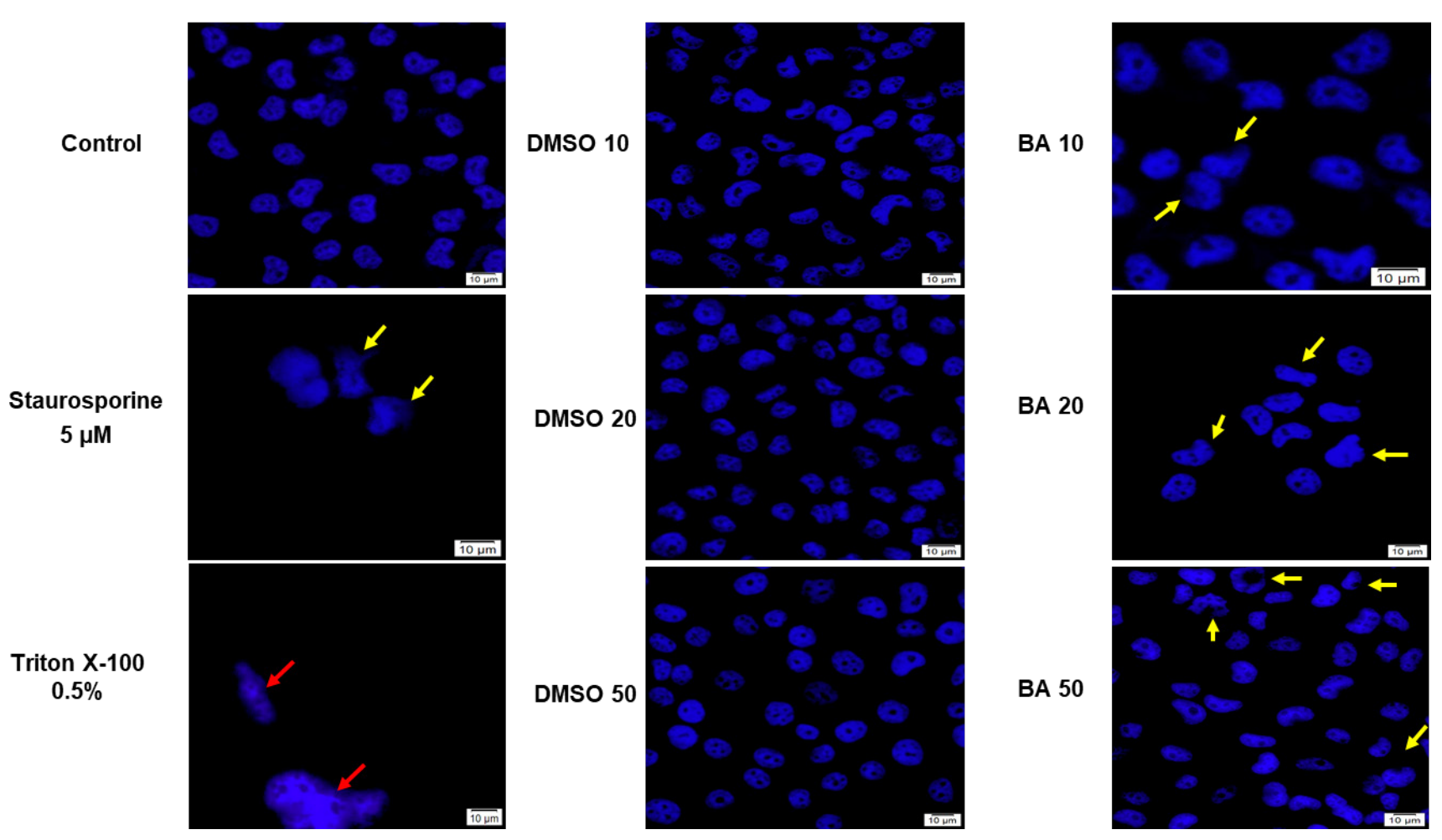

Figure 5. Nuclear staining using Hoechst 33342 in A375 cells after treatment with BA (10, 20 and $50 \mu \mathrm{M})$ and DMSO for $24 \mathrm{~h}$. The pictures were taken at $24 \mathrm{~h}$ post-treatment. Staurosporine solution $(5 \mu \mathrm{M})$ represents the positive control for apoptotic changes at nuclear level and Triton X-100 solution (0.5\%) for necrosis. The yellow arrows represent signs of apoptosis as nuclear shrinkage or nuclear fragmentation, and the red arrow indicates signs of necrosis as cellular membrane disruption. The scale bar was $10 \mu \mathrm{m}$.

The BA concentrations selected to perform this assay were 10, 20 and $50 \mu \mathrm{M}$ based on cell viability and cytotoxicity results. Our results indicated that with increasing concentrations the apoptotic signs become more evident, as follows: nuclear shrinkage (a morphologic hallmark of apoptosis onset-BA $10 \mu \mathrm{M}$ ), nuclear fragmentation, presence of apoptotic bodies and chromatin condensation (yellow arrows), features similar with the ones observed after Staurosporine $(5 \mu \mathrm{M})$ treatment-the positive control for apoptosis induction. No signs of necrosis (red arrows) were identified in BA-treated cells at the concentrations tested (Figure 5).

These results suggest that BA triggers a dose-dependent cytotoxic effect in melanoma cells by reducing cells viability and inducing apoptotic features: morphological alterations of both the nucleus and cytoplasm.

\subsection{BA Treatment Impacts on Mitochondrial Membrane Potential in a Dose-Dependent Manner}

The apoptotic-like cytotoxicity induced by BA treatment in A375 cells and the previously described capacity of BA to induce apoptosis via the mitochondrial pathway, prompted us to check the impact of BA on the mitochondrial membrane potential integrity that represents a hallmark of apoptosis-related cell death. The JC-1 mitochondrial fluorescent probe was used to highlight the effects of BA. The predominance of red fluo- 
rescence indicates polarized mitochondria and cells unaffected by apoptosis, whereas the predominance of green fluorescence indicates depolarized mitochondria and dead cells. Our findings showed that BA-treated cells with $50 \mu \mathrm{M}$ were predominantly green, what indicates a clear depolarization of mitochondria, a similar profile being also observed in $10 \mu \mathrm{M}$ BA-treated cells but also the red fluorescence was detected (Figure 6). DMSO-treated cells at both concentrations tested $(10$ and $50 \mu \mathrm{M})$ exhibited a fluorescent aspect (predominantly red) as control cells (untreated), indicating viable cells with polarized mitochondria (Figure 6). The red (JC-1 aggregates)/green (JC-1 monomers) ratio was $>1$ in control cells what indicates healthy cells with polarized mitochondria, whereas in the other groups of cells (BA 10 and $50 \mu \mathrm{M}$, and CCCP-treated) the ratio was $<1$ (Figure 6).
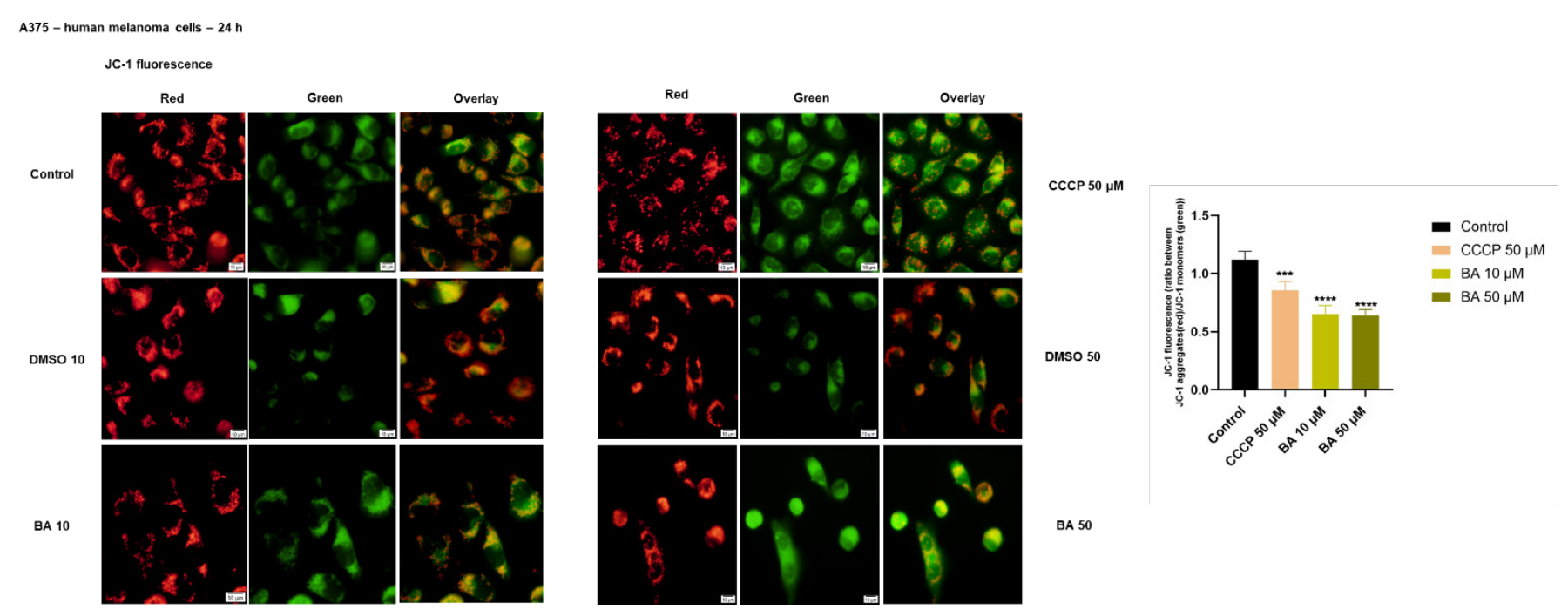

Figure 6. Mitochondrial membrane potential evaluation using JC-1 mitochondrial staining in A375 cells after treatment with BA $(10$ and $50 \mu \mathrm{M})$ and DMSO for $24 \mathrm{~h}$. The pictures were taken at $24 \mathrm{~h}$ post-treatment. CCCP $(50 \mu \mathrm{M})$ represents the positive control for mitochondrial depolarization. The graph represents the quantification of fluorescence intensity expressed as JC-1 aggregates (red)/JC-1 monomers (green) ratio. The data represent the mean values \pm SD of four independent measurements. One-way ANOVA analysis was applied to determine the statistical differences in rapport with control group followed by Dunnett's multiple comparisons post-test ${ }^{* * *} p<0.001$ and $\left.{ }^{* * * *} p<0.0001\right)$.

\subsection{BA Stimulation Induces Changes in Mitochondrial Markers mRNA Expression}

Since it is known that BA induces apoptosis in cancer cells via the intrinsic pathway involving mitochondria and the data regarding the role played by the pro- and antiapoptotic markers in this process is still debatable, we further verified the effect of BA on pro-apoptotic (Bid, Bax, Bak, and Bad) and anti-apoptotic markers (Bcl-2 and Bcl-XL) mRNA expression (Figure 7). The sub-cytotoxic concentration of BA-10 $\mu \mathrm{M}$ elicited an up-regulation of mRNA expression for most of the pro-apoptotic markers (Bax, Bad and Bak), except for Bid, the most significant increase in expression being calculated for Bak. BA treatment had no impact on Bcl-XL anti-apoptotic marker, whereas in the case of Bcl-2 it was also observed an upregulation (Figure 7). Moreover, we verified the impact of BA on caspase 3, caspase 8 and Apaf 1 mRNA expression and noticed a downregulation of these markers' expressions in BA-treated cells $(10 \mu \mathrm{M})$ as compared to DMSO-treated cells (data not shown) that did not reach statistical significance. 


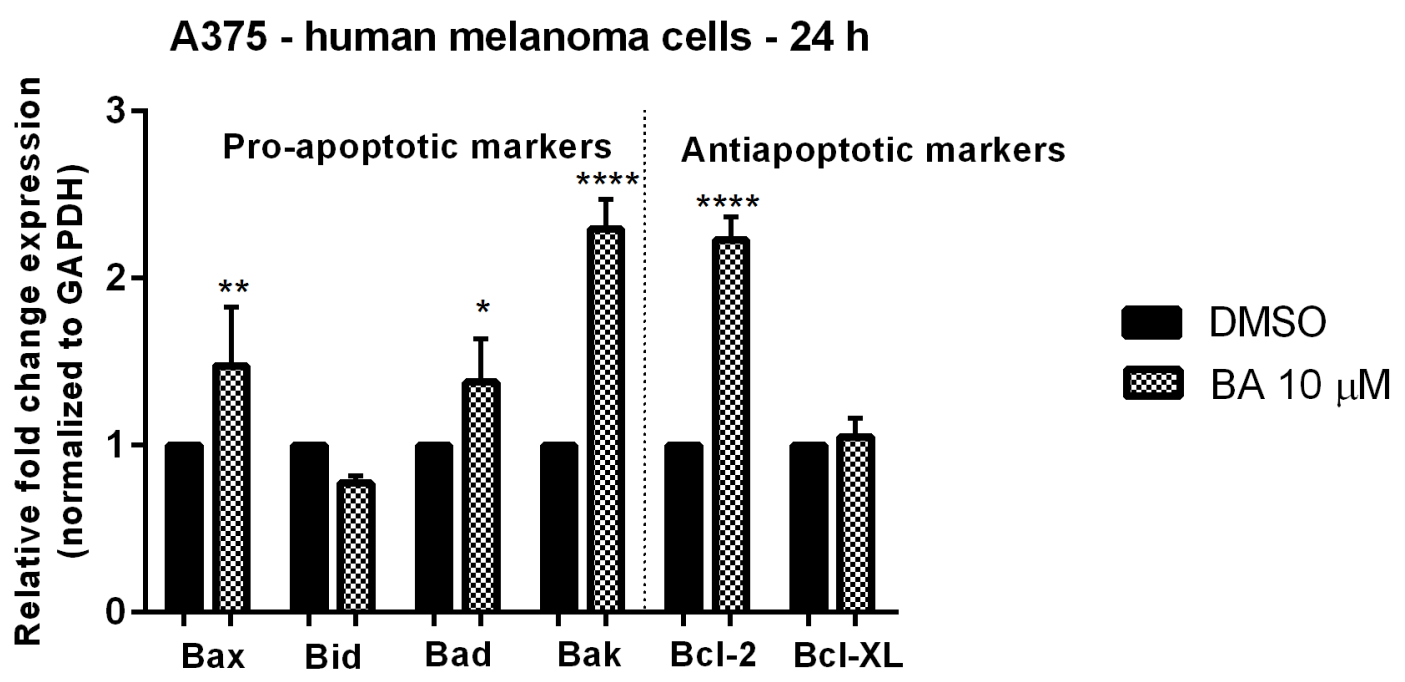

Figure 7. Relative fold expression of mRNA expression of pro- and anti-apoptotic mitochondrial markers in A375 cells after stimulation with BA $(10 \mu \mathrm{M})$ for $24 \mathrm{~h}$. The expressions were normalized to GAPDH and DMSO was used as control. Data represent the mean values \pm SD of three independent experiments. One-way ANOVA with Dunnett's post-test was applied to determine the statistical differences in rapport with DMSO stimulated cells $\left({ }^{*} p<0.05,{ }^{* *} p<0.01\right.$, and $\left.{ }^{* * *} p<0.0001\right)$.

\subsection{Impact of BA on Human Melanoma Cells Morphology and Cellular Organelles}

Changes in mitochondria morphology and localization are common features in melanoma cells as a consequence of the tumor metabolic reprogramming. To verify the localization of mitochondria in human melanoma cells-A375, was used a specific antibody-Anti COX IV mitomarker (green). In control cells, the fluorescence distribution was detected throughout the cell, whereas in the presence of BA it was concentrated around the nucleus, what could be considered that mitochondria are localized perinuclear (Figure 8). Phalloidin staining used to visualize F-actin fibers, indicated a slightly different distribution of these fibers in BA-stimulated cells as compared to control cells (unstimulated): the fluorescence is more concentrated at the edges of the cells as compared to control cells that present an evenly distribution of these fibers in the whole cell (Figure 8). The DMSO-treated presented a similar distribution of both mitochondria and actin fibers as the control cells (data not shown).

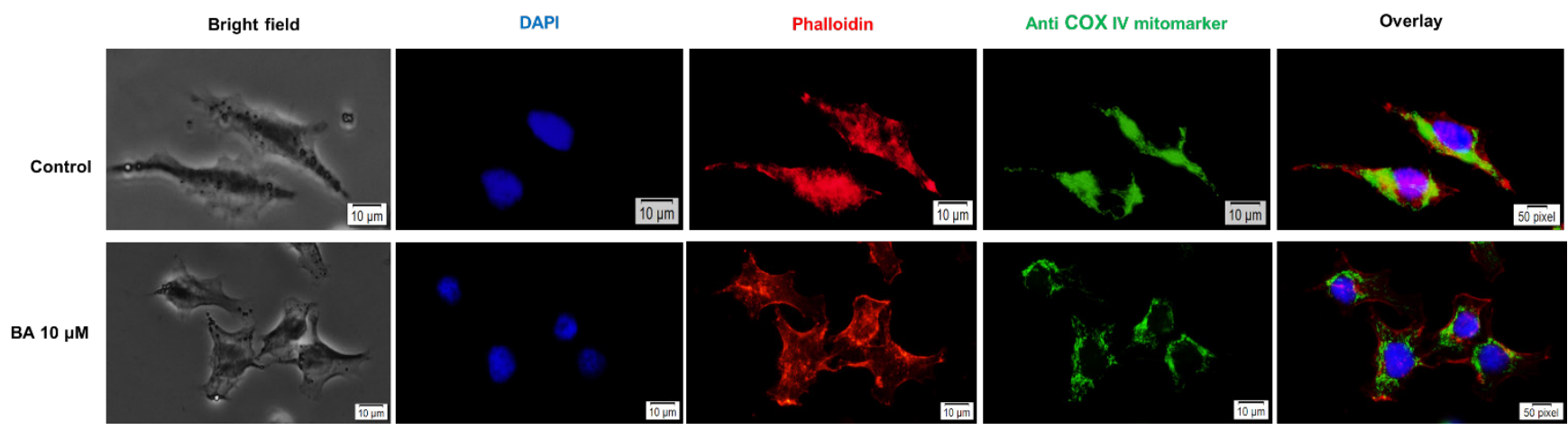

Figure 8. The impact of BA $(10 \mu \mathrm{M}) 24 \mathrm{~h}$ stimulation in A375 cells on: (a) nuclei-DAPI staining (blue), (b) F-actin fibersPhalloidin (red) and (c) COX IV mitochondrial marker (green). The pictures were taken using $40 \times$ objective at a scale bar of $10 \mu \mathrm{m}$.

\subsection{BA Treatment Modulates the Bioenergetic Profile of A375 Cells}

In our study, the Seahorse XFe24 extracellular flux analyzer was used to evaluate the bioenergetic profile of A375 human melanoma cells treated for $24 \mathrm{~h}$ with BA in increas- 
ing concentrations $(5,10$, and $50 \mu \mathrm{M})$. Both cellular OCR (oxygen consumption rate), the indicator of oxidative phosphorylation, and ECAR (extracellular acidification rate), the marker of glycolytic metabolism, were simultaneously monitored; the ECAR values were automatically converted to proton production rates (PPR) in order to directly reflect the efflux of lactic acid (Figure 9). By inhibiting mitochondrial complex V, oligomycin injection blocks the intracellular ATP synthesis via OXPHOS which is translated in a decrease of OCR (Figure 9); thereby, energy production is shifted to glycolysis and ECAR increases (Figure 9). The injection of the uncoupling agent, FCCP, significantly increases OCR (Figure 9) as more $\mathrm{O}_{2}$ is consumed to pump the excess protons back across the mitochondrial membrane, while ECAR remains increased due to cells' attempt to maintain their energy balance by using glycolysis to generate ATP (Figure 9). Antimycin A, by inhibiting mitochondrial CIII stops the electron flow in the ETC which drastically reduces OCR (Figure 9), while ECAR is not significantly modified (Figure 9), since cells shifted to a glycolytic state, in order to maintain their energy balance. As seen in Figure 9, the PPR profile was similar to ECAR's one.

\section{OCR Data}

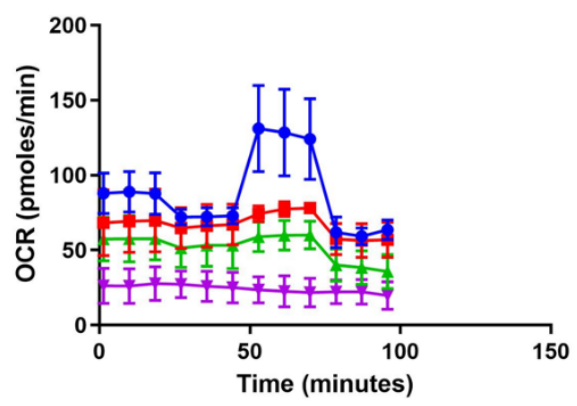

$$
\begin{aligned}
& \text { - Control } \\
& \text { - BA } 5 \\
& \text { - BA } 10 \\
& \text { - BA } 50
\end{aligned}
$$

ECAR Data

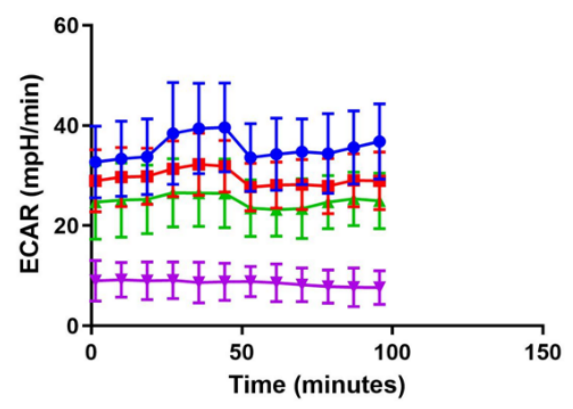

$$
\begin{aligned}
& \text { - Control } \\
& - \text { BA } 5 \\
& =\text { BA } 10 \\
& \text { - BA } 50
\end{aligned}
$$

PPR Data
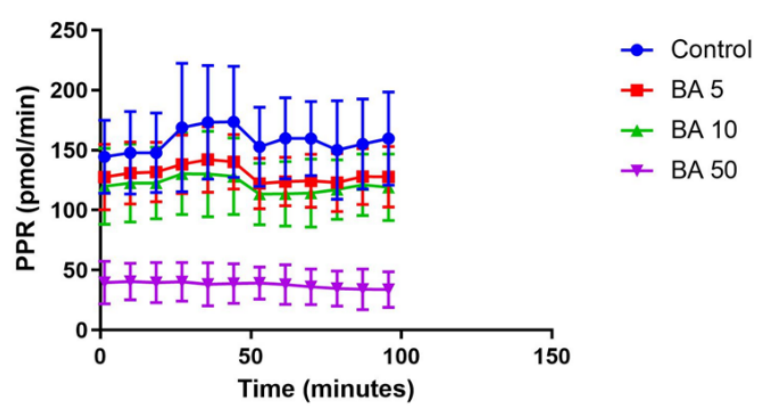

Figure 9. Summary traces of the bioenergetic profile of A375 cells: Control—untreated cells; BA 5-cells treated with $5 \mu \mathrm{M}$ betulinic acid; BA 10—cells treated with $10 \mu \mathrm{M}$ betulinic acid; BA 50—cells treated with $50 \mu \mathrm{M}$ betulinic acid. OCR was expressed in units of nmoles $/ \mathrm{min} / \mathrm{no}$ of cells, ECAR in $\mathrm{mpH} / \mathrm{min} /$ no of cells, and PPR in pmoles/min/no of cells. 
We showed here that both global OCR and ECAR (i.e., measured at the end of each experiment) were decreased in a concentration-dependent manner when A375 cells were treated with BA for $24 \mathrm{~h}$, yet the concentration of $5 \mu \mathrm{M}$ did not show a significant change of ECAR. Regarding the highest concentration of BA used in our experiments $(50 \mu \mathrm{M})$, we found out that A375 cells had the lowest basal respiration and did not longer respond to the protocol used to modulate both glycolytic and mitochondrial pathways for ATP production (Figure 9); accordingly, the global OCR and ECAR presented the highest decline as compared to the untreated cells (Figure 10). In the end, the proton production rates (PPR) underwent changes very similar to ECAR in cells treated with BA. A limiting problem linked with BA is the poor water solubility. Thereby, BA was dissolved in DMSO, and our data showed that all tested DMSO concentrations did not interfere with the bioenergetic profile of A375 cells (Figure 10).
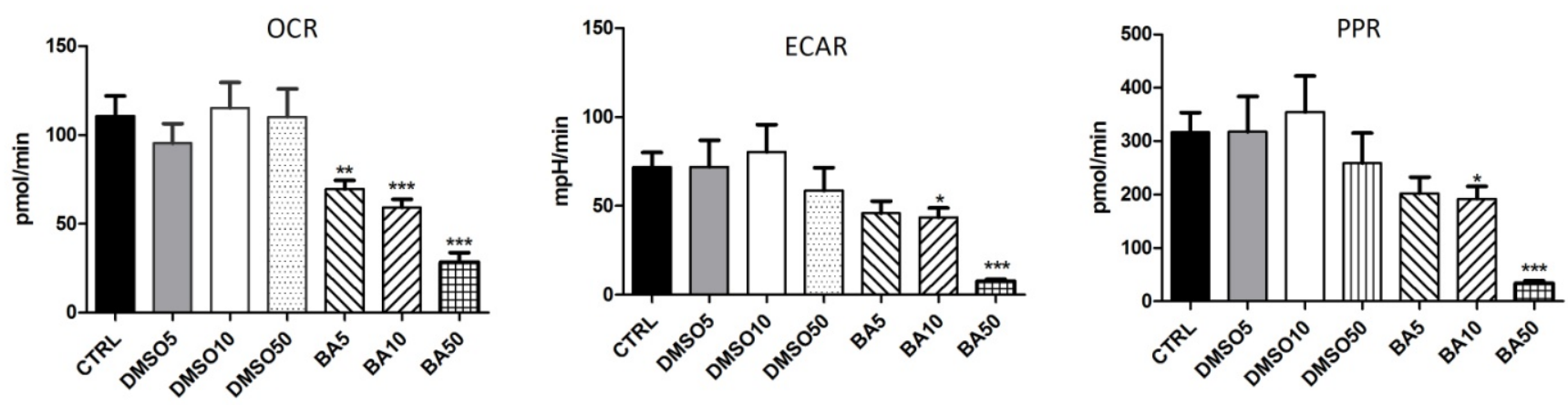

Figure 10. The effects of a $24 \mathrm{~h}$ treatment with BA $(5,10$ and $50 \mu \mathrm{M})$ on OCR, ECAR, and PPR $\left(\mathrm{n}=14-20 /\right.$ group. ${ }^{*} p<0.05$ vs. untreated controls, $\left.{ }^{* *} p<0.01,{ }^{* * *} p<0.001\right)$.

\subsection{BA-Mediated Changes on Mitochondrial Respiratory Parameters in A375 Human Melanoma Cells}

To gain insights into the induced mitochondrial metabolic impairment in melanoma cells, we further evaluated the key parameters of mitochondrial respiration in permeabilized A375 cells treated with the optimal concentration of BA $(10 \mu \mathrm{M})$ by the help of HRR (high-resolution respirometry). Our data showed that the stimulation of A375 cells with BA $(10 \mu \mathrm{M})$ for $24 \mathrm{~h}$ determined a significant decrease of basal respiration rates-leak states (State $2_{\mathrm{CI}}$ and State $4_{\mathrm{CI}+\mathrm{II}}$, measured after oligomycin addition) and routine respiration vs. DMSO-stimulated cells. A decline of active respiration (both $\mathrm{OXPHOS}_{\mathrm{CI}}$ and OXPHOS $_{\mathrm{CI}+\mathrm{II}}$ ) was also triggered by BA (Figure 11). Furthermore, our results indicate that BA significantly inhibited the maximal respiratory capacity $\left(\right.$ ETS $\left._{\mathrm{CI}+\mathrm{II}}\right)$ (Figure 11). Based on these findings, were calculated the corresponding respiratory flux ratios (R/E, L/E and RCR), indicators of mitochondrial coupling and OXPHOS efficiency, respectively (Table 1). The results summarized in Table 1 show that BA stimulation induced an increase of both $\mathrm{R} / \mathrm{E}$ and $\mathrm{L} / \mathrm{E}$ ratios, whereas RCR is decreased (Table 1).

Table 1. Flux control ratios calculated for permeabilized A375 cells treated with DMSO and BA-10 $\mu$ M.

\begin{tabular}{ccc}
\hline Flux Control Ratios & \multicolumn{2}{c}{ 24 h Stimulation } \\
\hline & DMSO & BA \\
\hline R/E & $0.604 \pm 0.145$ & $0.975 \pm 0.022^{* *}$ \\
L/E & $0.154 \pm 0.040$ & $0.299 \pm 0.098^{*}$ \\
RCR & $4.530 \pm 1.398$ & $2.785 \pm 0.953^{*}$
\end{tabular}

CI-complex I; CII-complex II; R/E-Routine/ ETS $_{\mathrm{CI}+\mathrm{II}} ; \mathrm{L} / \mathrm{E}-\mathrm{LEAK}$ (State 4 CI+II)/ETS $\mathrm{CI+II}$; RCROXPHOS $_{\mathrm{CI}+\mathrm{II}} /$ LEAK (State 4 CI+II). 


\section{A375 - human melanoma cells - 24 h}

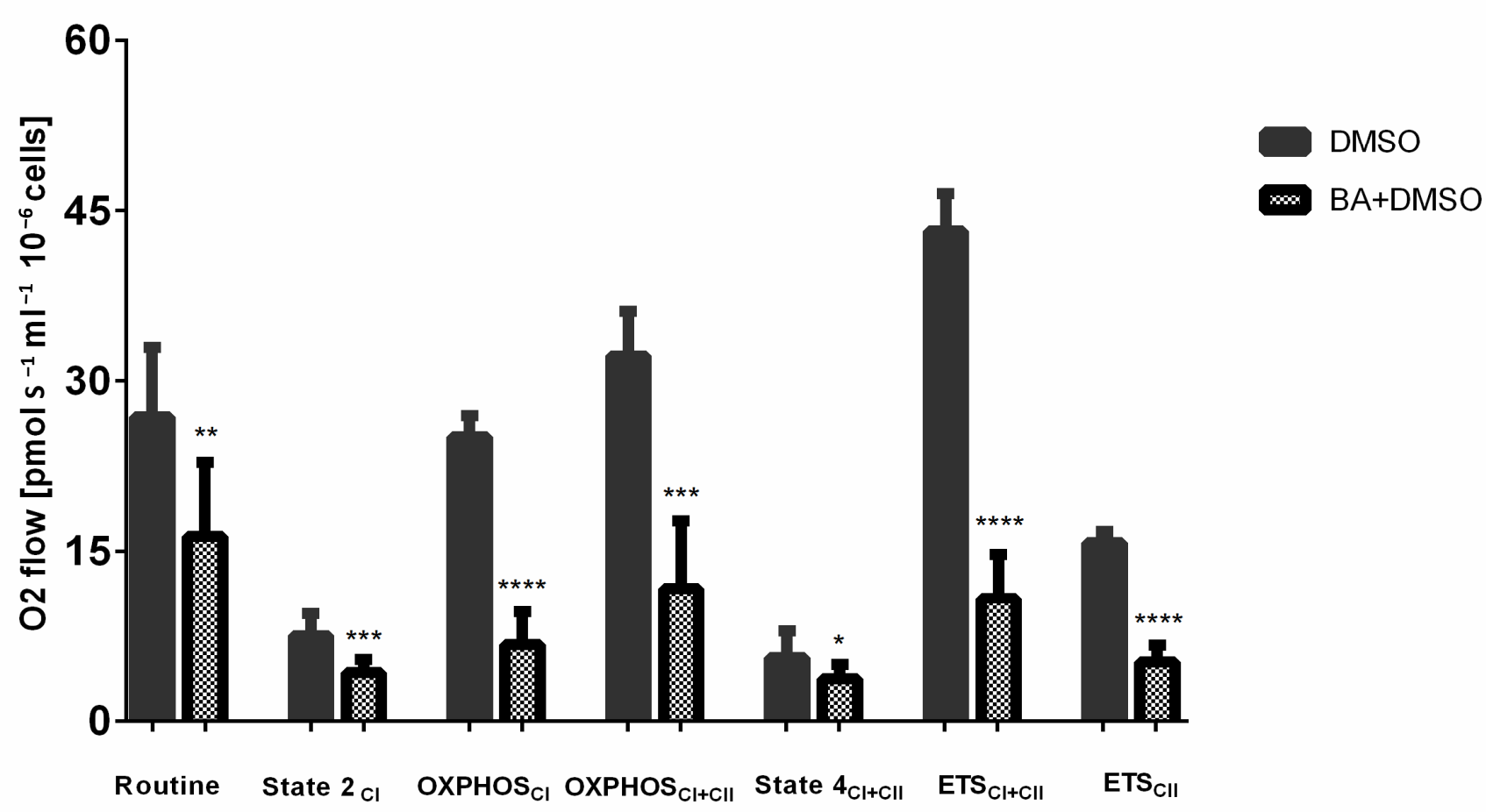

Figure 11. Respiration of permeabilized human melanoma cells-A375 following $24 \mathrm{~h}$ stimulation with BA $(10 \mu \mathrm{M})$ and DMSO. Data represent the mean values \pm SD of three independent experiments. Unpaired $t$ test with Welch's correction was applied to determine the statistical differences vs. DMSO-incubated cells $\left({ }^{*} p<0.05,{ }^{* *} p<0.01,{ }^{* * *} p<0.001\right.$, and $\left.{ }_{* * * *} p<0.0001\right)$. The results were normalized to cells stimulated with DMSO (the vehicle used for BA solubilization). The following respiratory parameters were assessed: Routine-respiration of cells suspended in a substrate-free media; State $2_{\mathrm{CI}}$ - the respiration in basal conditions, OXPHOS $\mathrm{CI}_{\mathrm{C}}$-active respiration through CI; OXPHOS $\mathrm{CI+II}$-maximal active respiration driven by $\mathrm{CI}$ and $\mathrm{CII}$; State $4_{\mathrm{CI}+\mathrm{II}}$ - basal respiration dependent on both $\mathrm{CI}$ and $\mathrm{CII}$; $\mathrm{ETS}_{\mathrm{CI}+\mathrm{II}}$-maximal respiratory capacity of the electron transport system after FCCP titrations; ETS $_{\mathrm{CII}}$-electron transport system dependent only on CII.

Data represent the mean values $\pm \mathrm{SD}$ of three independent experiments. Unpaired $t$ test with Welch's correction was applied to determine the statistical differences vs. DMSOincubated cells $\left({ }^{*} p<0.05 ;{ }^{* *} p<0.01\right)$.

\section{Discussion}

This study was particularly aimed at gathering novel insights regarding the effects of betulinic acid on mitochondrial bioenergetics in human melanoma cells, as a metabolism-driven approach to fully understand the antitumoral property of this bioactive phytocompound. The main working hypothesis was that the antimelanoma mechanism of action of BA involves the modulation of mitochondrial energetic metabolism. The major findings in this respect are as follows: (i) a dose-dependent inhibitory effect on both the oxygen consumption rate (OCR) and extracellular acidification rate (ECAR) (Figure 10) (the classic markers of oxidative phosphorylation and glycolysis, respectively) and (ii) a significant decrease elicited by a sub-toxic concentration $(10 \mu \mathrm{M})$ of both complex I and II-supported respiratory parameters (in particular, the active respiration-OXPHOS, and the maximal respiratory capacity of the electron transfer system-ETS, respectively) (Figure 11 and Table 1). In addition, we demonstrated that BA elicited a dose-dependent cytotoxic effect characterized by apoptotic features: morphological alterations (nuclear fragmentation, apoptotic bodies-Figures 4 and 5), a decrease in mitochondrial membrane potential (Figure 6), up-regulation of pro-apoptotic markers mRNA expression (Bax, Bad 
and Bak) (Figure 7) and changes in mitochondria morphology and localization in the A375 melanoma cell line (Figure 8).

Betulinic acid is included in the class of mitocans (abbreviation that was formed from mitochondria and cancer), agents that trigger cell death by targeting mitochondria [23]. BA has unequivocally proven its efficacy both in vitro and in vivo against a plethora of malignancies (melanoma, colorectal cancer, lung, hepatocellular, breast, prostate, stomach, pancreatic, neck and head carcinoma, ovarian, glioblastoma, chronic myeloid leukemia) and its selectivity, inducing no/very low effects on healthy/normal cells even at doses as high as $500 \mathrm{mg} / \mathrm{kg}$ body weight $[17,24]$. Moreover, BA formulated for topical application ( $20 \%$ betulinic acid ointment) was assessed in a phase I/II clinical trial for dysplastic nevi that can evolve towards melanoma; unfortunately, the study was suspended due to funding restriction [24-26].

View the key role played by metabolic pathways in cancer survival and progression, we assessed the mitochondrial effects of BA. In contrast to normal cells that rely on oxidative phosphorylation, tumor cells undergo a metabolic reprogramming, switching from oxidative phosphorylation to aerobic glycolysis [27]. In fact, two metabolic 'programs' have been reported to occur in tumors: one specific for actively proliferating cancer cells that require both oxidative phosphorylation and glycolysis (to facilitate the biosynthesis pathways that control proliferation) and a program specific for a subset of quiescent/slowcycling cells that relies on mitochondrial respiration (to undergo continuous growth and gain intrinsic therapeutic resistance) [12]. It is the latter program that makes mitochondria a reliable target for the anticancer agents.

Indeed, it has been recently reported that both the aggressiveness of melanoma and resistance to treatment were assigned to the presence of a subset of cells that rely on respiration [12]. An augmented dependency on mitochondrial respiration was described in melanoma cells that express high levels of PGC1 $\alpha$ (peroxisome proliferatoractivated receptor $\gamma$ coactivator $1 \alpha$-a master regulator of mitochondria) and the BRAF gene $[28,29]$. By contrast, tumor cells that present a defective OXPHOS became extremely sensitive to cytotoxic drugs, since mitochondria assure from 40 to $75 \%$ of cancer cells ATP demands [12,27].

Targeted therapy that specifically inhibits BRAF and MEK pathways also inhibit glycolysis and is nowadays the mainstay of melanoma therapy; since an increase in oxidative phosphorylation has been reported to contribute to drug resistance, the inhibition of mitochondrial respiration has emerged as viable therapeutic strategy to overcome the resistance to pharmacological inhibitors $[30,31]$. Therefore, scientific efforts are aimed at discovery of compounds capable to inhibit both glycolytic and mitochondrial pathways for ATP generation $[32,33]$.

In the present study, we analyzed the BA effects on human melanoma cells using the Seahorse XFe24 extracellular flux analyzer and showed the dose-dependent inhibition of both mitochondrial respiration and glycolysis. Our data are in line with a recent study demonstrating that citrate synthase activity, glycolysis rate and carbon flux through the TCA cycle were inhibited in BA-loaded nanoliposomes-treated colorectal cancer cells; the results were confirmed by the glycolysis stress test in which ECAR values revealed that both the basal glycolysis and the maximum glycolytic capacity were reduced by BA-loaded nanoliposomes [34].

In order to further dissect the effects of the phytocompound on mitochondrial respiration, we performed high-resolution respirometry studies (Oxygraph-2k, Oroboros Ltd., Innsbruck, Austria) using the standardized SUIT protocol in permeabilized human melanoma cells treated with $10 \mu \mathrm{M}$ BA. To the best of our knowledge, this is the first study that demonstrates the inhibitory effect of BA on respiratory parameters in these cells. The above-mentioned concentration was selected based both on the Seahorse data and our previous publications where no toxicity was recorded for HaCaT cells (normal human keratinocytes). 
As depicted in Figure 11, BA stimulation elicited an overall inhibition of cellular respiration in A375 melanoma cells by significantly decreasing the following parameters: basal respiration, active respiration, and maximal uncoupled respiration. The decrease of State 2 and State 4 (leak) suggests that the treatment with BA decreases oxygen consumption when the phosphorylation system is in an inactivated state, presumably due to a decrease in proton leak/slip across the mitochondrial membrane. Moreover, the significant decrease of both CI and CII-driven OXPHOS in parallel with the ETS mitigation unequivocally demonstrated that $\mathrm{BA}$ inhibits the active respiration and decreases the maximal respiratory capacity of the electron transfer system. A decline of maximal respiratory capacity is considered a reliable marker of a mitochondrial dysfunction [35]. Of note, the impairment of ATP production has been considered a promising therapeutic strategy for cancer since the compounds that act by inhibiting mitochondrial ATP production can trigger cell death in poorly perfused tumors and in those that highly rely on oxidative phosphorylation [36].

A similar mitochondrial dysfunction (inhibition of cellular respiration and impairment of mitochondrial electron transport chain complexes) in melanoma cells was described after stimulation with honokiol, a small molecule with anticancer properties, an activity that was associated with an augmented pro-apoptotic effect [37]. The impairment of oxidative phosphorylation and induction of oxidative stress was described as the mechanism exerted by resveratrol to inhibit the proliferation of different cancer cell lines (HeLa, MDA-MB-231, MCF7, SiHa and A549) [38]. Also, a recent paper showed that BRAF-mutant melanoma brain metastasis could be prevented by suppressing mitochondrial respiration [39].

Another druggable target in cancer is the phenomenon of uncoupling since increased uncoupling was related to tumor progression [40]. The uncoupling of oxidative phosphorylation is defined as significant reduction of the active respiration and a marked increase in the basal respiratory rates (with subsequent decrease in the respiratory control ratio). Interestingly, BA does not exert the effect of a typical uncoupler, described as an increased State 2 and State 4 respiratory rates [41-43], hence it induces mitochondrial dysfunction without increasing the proton transport across the inner mitochondrial membrane.

The flux respiratory ratios represent reliable indicators of changes that occur in mitochondrial respiration in response to different agents. The flux ratios that were calculated in the present study were: $\mathrm{R} / \mathrm{E}$-routine control ratio, $\mathrm{L} / \mathrm{E}$ - leak control ratio, and RCRrespiratory control ratio. In normal cells, $\mathrm{R} / \mathrm{E}$ ratio varies from 0.2 to 0.4 [44]. Values $\geq 0.5$, as obtained for BA treated cells (0.975, Table 1$)$, might suggest either an increased uncoupling, or defects in substrate oxidation/ETS complexes activity that led to the limitation of respiratory capacity, the latter being true for the case of BA. L/E ratio is an indicator of mitochondrial coupling with values as 0.0 indicating fully coupled mitochondria whereas 1.0 is attributed to fully uncoupled mitochondria [44]. The mean values of $\mathrm{L} / \mathrm{E}$ obtained for BA treated cells $(0.299$, Table 1$)$ suggest that human melanoma cells contain rather coupled mitochondria. As for the RCR ratio our results show a decrease in BA-treated A375 cells, demonstrating once more the mitochondrial dysfunction induced by BA. A decrease of mitochondrial membrane potential was induced by BA in a dose-dependent manner (Figure 6), finding that could be correlated with the reduction of maximal respiratory capacity following BA treatment.

The second important finding of the present study is represented by the BA-related toxicity in A375 human melanoma cells.

The cell viability results confirm the selective cytotoxicity of BA on human melanoma $\left(68.22 \%\right.$ viable $\mathrm{A} 375$ cells $\left.-\mathrm{IC}_{50}=16.91 \mu \mathrm{M}\right)$ and the low toxicity on normal cells $(81.42 \%$ $\mathrm{HaCaT}$ viable cells) after a $24 \mathrm{~h}$ stimulation with the highest concentration of $\mathrm{BA}-50 \mu \mathrm{M}$ (see Figures 1 and 3). A cytotoxic effect of BA on melanoma cells was also described in other studies, with a range of $\mathrm{IC}_{50}$ between 1 to $76 \mu \mathrm{g} / \mathrm{mL}$ dependent on cell type [17,24]. Liebscher and coworkers proved that BA induced cytotoxicity not only on human melanoma cells-A375 $\left(\mathrm{IC}_{50}=13.3 \mu \mathrm{M}\right)$, but also on equine melanoma cell lines obtained from grey horses [45]. Our previous results showed that a concentration of $10 \mu \mathrm{M}$ BA did not influence A375 cells viability but induced an epithelial-to-mesenchymal transition in these cells while a higher 
concentration $(50 \mu \mathrm{M})$ proved to be toxic [46]. As regards the effect of BA on HaCaT cells, our data indicate that concentrations higher than $10 \mu \mathrm{M}$ reduced cell viability and initiated morphological changes (cellular shape and nuclear alterations) (Figure 1). In a previous study conducted by Martins et al. [21] it was shown that BA $(20 \mu \mathrm{M})$ triggers cell senescence in $\mathrm{HaCaT}$ cells by altering lipid bilayers, injuring mitochondria and lysosomes membranes and impairing autophagy. Taken together, these data support our cytotoxicity findings.

Since 1995, when BA was placed in the spotlight as an antimelanoma compound by Pisha et al. [47], a considerable number of studies were carried out to define the molecular pathways involved in BA-mediated antitumor activity, but several pieces are still missing from the complete picture. A mechanistic pathway that was initially suggested was induction of apoptosis via a direct effect on mitochondria involving Bcl-2 family, permeabilization of mitochondria outer membrane and activation of caspases [48]. The induction of apoptosis via the "intrinsic" or mitochondrial pathway is regulated by the Bcl-2 family of proteins. This family includes almost 20 members that are divided in antiapoptotic (contain the four Bcl-2 homology domains-BH1-4: Bcl-2, Bcl-xL, Mcl-1-myeloid cell leukemia 1, A1 and Bcl-w) and pro-apoptotic (effector proteins with all BH1-4 domains: Bak and Bax and the BH3-only proteins: Bad, Bid, Bik, Bim, Bmf, bNIP3, HRK, Noxa and PUMA) proteins with regulatory functions in cell survival and apoptosis machinery by controlling the outer mitochondrial membrane permeabilization [49,50]. A deregulated function of Bcl-2 family is a common feature in different types of human cancers such as renal, stomach, and ovarian cancers, brain tumors, leukemia, and melanoma [16,51]. The anti-apoptotic members of Bcl-2 family act as keepers of the outer mitochondrial membrane integrity by linking and suppressing the activity of pro-apoptotic members, Bax (Bcl-2 associated x protein) and Bak (Bcl-2 antagonist killer 1) that promote the MOMP (mitochondrial outer membrane permeabilization) followed by apoptosis initiation [49].

Several lines of evidence suggest that BA modulates the Bcl-2 family proteins in a tumor-dependent manner, as follows: (i) upregulation of Bax pro-apoptotic protein in neuroblastoma, glioblastoma and melanoma cells; (ii) up-regulation of anti-apoptotic Bcl-2 protein in glioblastoma and neuroblastoma; (iii) no effect on Bak and Bad in melanoma cells and on Bcl-2 in squamous cell carcinoma cells; iv) increased expression of Mcl-1 protein in melanoma cells; (v) no significant effects on Bcl-xL in melanoma, neuroblastoma and glioblastoma cells; (vi) downregulation of Bcl-2 and Bcl-xL expressions in human multiple myeloma cells; and (vii) up-regulation of Bad expression and no effect on Bcl-xL in HeLa cells [52-57]. In the light of these findings, we assessed the effect of BA (10 $\mu \mathrm{M})$ on the expression of both pro-apoptotic (Bax, Bak, Bad and Bid) and anti-apoptotic (Bcl-2 and Bcl-xL) markers. Accordingly, we showed that BA induced an up-regulation of Bax, Bad and Bak, and no effect on Bid expression in human melanoma cells. Regarding the anti-apoptotic marker Bcl-XL, its mRNA expression was not influenced by BA treatment, whereas in the case of $\mathrm{Bcl}-2$ it was recorded an up-regulation (Figure 7). An interesting and unexpected finding was the upregulation of Bcl-2 expression by BA treatment. A similar case was described by Wick et al. in glioma cells [55]. An upregulation of another antiapoptotic marker, also a member of the Bcl-2 family, Mcl-1, by BA treatment was observed by Selzer et al. in melanoma cells [58], a phenomenon that could not be clearly explained by the authors, but they stated that BA-induced apoptosis was a late event that occurred after 24-48 h and the stimulation of Mcl-1 expression was observed in the first hours of treatment, and somehow speculated that this event could be an adaptative response of the cells to a cytotoxic stimulus.

It is well-known that a mitochondrial dysfunction is accompanied by phenotypical and morphological cellular modifications as an adaptive response to a potential injury [7] making the staining of actin microfilaments and tubulin fibers a mandatory test in the evaluation of compounds that target mitochondria. Actin microfilaments represent key components of the cytoskeleton that suffer conformational changes as a consequence of different cellular stressors and/or modifications of nucleotide binding [7]. To expand upon the findings stated before, we assessed the BA effect on actin microfilaments in 
A375 cells by performing immunofluorescence staining assays. Our results indicate a reorganization of actin microfilaments stained with phalloidin (red color) in BA-treated cells with a distribution focused mainly to the edges of the cells as compared to control and DMSO-treated cells that present a longitudinal uniform distribution within the cell (Figure 8).

Mitochondria are dynamic organelles qualified to change the shape, size and subcellular localization in order to fulfill their particular biological and energetic demands [37].

The mitochondrial morphology in A375 cells was evaluated by the means of immunofluorescence staining in the presence of anti-COX IV antibody. MitoTracker (green) staining revealed in control and DMSO-treated cells a distribution of the mitochondria across the cellular cytoplasm, whereas in BA-treated cells, mitochondria appear tightly organized at the periphery of the nuclear envelope (Figure 8). These morphological changes were also described in other studies that investigated compounds targeting mitochondria such as ethidium bromide and honokiol $[7,37]$. Collectively, these findings confirm the impairment of mitochondrial morphology induced by BA stimulation in melanoma cells.

\section{Materials and Methods}

\subsection{Reagents}

The reagents applied in the present study: $\mathrm{MgCl}_{2} \times 6 \mathrm{H}_{2} \mathrm{O}$, EGTA (ethylene glycol-bis( $\beta$ aminoethyl ether)- $\mathrm{N}, \mathrm{N}, \mathrm{N}^{\prime}, \mathrm{N}^{\prime}$-tetraacetic acid), taurine, $\mathrm{KH}_{2} \mathrm{PO}_{4}$, lactobionic acid, sucrose, HEPES (4-(2-hydroxyethyl)-1-piperazineethanesulfonic acid), BSA (bovine serum albu$\mathrm{min}$ ), digitonin, glutamate, malate, succinate, ADP (adenosine diphosphate), oligomycin, rotenone, antimycin A, FCCP (Carbonyl cyanide 4-(trifluoromethoxy)phenylhydrazone), betulinic acid (BA), and DMSO (dimethyl sulfoxide-the vehicle used for BA solubilization) were purchased from Sigma Aldrich, Merck KGaA(Darmstadt, Germany). All reagents used were of analytical purity. Cell culture media-Dulbecco's modified Eagle Medium (DMEM) and specific supplements were acquired from Sigma Aldrich, Merck KGaA (Darmstadt, Germany), ATCC (American Type Cell Collection, Lomianki, Poland) and Thermo Fisher Scientific, Inc. (Waltham, MA, USA). XFe24 well plates, XF sensor cartridges, and XF Assay media were provided by Agilent Technologies, Inc. (Santa Clara, CA, USA).

\subsection{Cell Lines and Cell Culture Conditions}

The HaCaT—immortalized human keratinocytes and A375 (ATCC ${ }^{\circledR}$ CRL-1619 ${ }^{\mathrm{TM}}$ ) human melanoma cell lines were purchased from CLS Cell Lines Service GmbH (Eppelheim, Germany) and American Type Culture Collection (ATCC, Lomianki, Poland), respectively. The cells were acquired as frozen items and kept in liquid nitrogen. HaCaT and A375 cells were cultured in specific media-Dulbecco's modified Eagle Medium (DMEM) high glucose $-4.5 \mathrm{~g} / \mathrm{L}$, supplemented with $10 \%$ fetal bovine serum (FBS) and antibiotic mixture (100 U/mL penicillin and $100 \mu \mathrm{g} / \mathrm{mL}$ streptomycin). The cells were kept in standard conditions: a humidified atmosphere with $5 \% \mathrm{CO}_{2}$ at $37^{\circ} \mathrm{C}$. Cell number was determined automatically using the cell counting device, Countess II Automated Cell Counter (Thermo Fisher Scientific, Inc., Waltham, MA, USA), in the presence of Trypan blue.

\subsection{Cytotoxicity Assessment}

MTT assay. Cell viability was evaluated by using the MTT (3-(4,5-Dimethylthiazol2-yl)-2,5-Diphenyltetrazolium Bromide) kit (Roche, Mannheim, Germany) according to the experimental protocol described in our previous studies [59]. In brief, $\mathrm{HaCaT}$ and A375 cells $\left(1 \times 10^{4} / 200 \mu \mathrm{L}\right.$ medium/well) were seeded in 96-well plates and stimulated with increasing concentrations $(0-50 \mu \mathrm{M})$ of BA solubilized in DMSO for $24 \mathrm{~h}$. The plates were incubated for $3 \mathrm{~h}$ at $37^{\circ} \mathrm{C}$ with $10 \mu \mathrm{L} /$ well of MTT reagent, followed by addition of buffer solution $(100 \mu \mathrm{L} /$ well $)$ and incubation at room temperature and dark for $30 \mathrm{~min}$. Absorbance measurement was performed at $570 \mathrm{~nm}$ using a $x^{\text {Mark }}{ }^{\mathrm{TM}}$ Microplate Spectrophotometer (Bio-Rad Laboratories, Inc., Hercules, CA, USA). The vehicle used for BA 
was dimethyl sulfoxide-DMSO for cell culture. The final concentration of DMSO did not exceed $1 \%$.

Evaluation of cellular morphology. Alterations of cellular morphology following the exposure to a test compound represent reliable clues for the identification of the type of induced cytotoxicity (i.e., cell death). Thus, we further monitored the impact of BA on cells' morphology using the Olympus IX73 inverted microscope (Olympus, Tokyo, Japan). The images were taken at $24 \mathrm{~h}$ post-treatment and were analyzed using the cellSens Dimensions v.1.8. Software (Olympus, Tokyo, Japan) as described previously [60,61].

Hoechst nuclear staining. Apoptotic cells were labelled by the means of Hoechst 33342 nuclear staining assay (Invitrogen, Carlsbad, CA, USA). The protocol consisted of the following steps: (i) treatment of cultured cells-A375 and HaCaT $\left(1 \times 10^{5}\right.$ cells $/ 1.5 \mathrm{~mL}$ medium/well) with different concentrations of BA in DMSO (10, 20 and $50 \mu \mathrm{M})$ for $24 \mathrm{~h}$; (ii) disposal of the medium containing the test compounds and addition of the staining solution- $0.5 \mathrm{~mL} /$ well (1:2000 in PBS); (iii) a 10-min incubation at room temperature and dark, and (iv) the final washing step (3x) with PBS. The pictures were taken using Cytation 1 (BioTek Instruments Inc., Winooski, VT, USA) and the Olympus IX73 inverted microscope (Olympus, Tokyo, Japan). The images were analyzed using the Gen5 ${ }^{\mathrm{TM}}$ Microplate Data Collection and Analysis Software (BioTek Instruments Inc., Winooski, VT, USA) and the cellSens Dimensions v.1.8. Software (Olympus, Tokyo, Japan). Staurosporine solution$5 \mu \mathrm{M}$-was used as positive control for apoptosis $\left(3 \mathrm{~h}\right.$ at $\left.37^{\circ} \mathrm{C}\right)$ and Triton $\mathrm{X}-100(30 \mathrm{~min}$ at $\left.37^{\circ} \mathrm{C}\right)-0.5 \%$ for necrosis [62].

\subsection{Mitochondrial Membrane Potential ( $\triangle \Psi)$ Assay (JC-1)}

Mitochondrial membrane potential $(\Delta \Psi)$ is considered a marker for cell health status and an essential indicator for mitochondrial function. To evaluate the impact of BA on $\Delta \Psi$ in A375 human melanoma cells, we used the cationic JC-1 Dye (Mitochondrial Membrane Potential Probe, Invitrogen, Carlsbad, CA, USA). The assay was performed according to the experimental protocol described by Sivandzade et al. [63] and was adapted to our laboratory conditions. Briefly, the A375 cells were seeded in 12-well plates and were treated with different concentrations of BA and DMSO $(10$ and $50 \mu \mathrm{M})$ for $24 \mathrm{~h}$. The JC- 1 solution was added to reach a final concentration of $2 \mu \mathrm{M}$ and the cells were incubated at $37^{\circ} \mathrm{C}$ for $30 \mathrm{~min}$. Visualization of the stained cells was performed using Olympus IX73 inverted microscope (Olympus, Tokyo, Japan). The red fluorescence mitochondrial signal was detected at $590 \mathrm{~nm}$ and is an indicator of JC-1 aggregates specific for polarized mitochondria (non-apoptotic cells). The green fluorescence is a specific marker for apoptotic and dead cells and was observed at an emission of $530 \mathrm{~nm}$ indicating that JC-1 dye remained in its monomeric form, a feature specific for depolarized mitochondria. The CCCP (carbonyl cyanide m-chlorophenylhydrazone) solution ( $50 \mu \mathrm{M}, 5 \mathrm{~min}$ ) was used as a positive control. The quantification of fluorescence intensity was calculated with ImageJ and Fiji software (National Institutes of Health, Bethesda, MD, USA) and the measurements of the images were performed by selecting a region of interest (ROI) that was measured by auto threshold according to the analysis software.

\subsection{Quantification of Apoptotic Markers by Real-Time PCR}

The total RNA content was extracted using peqGold RNAPureTM Package (Peqlab Biotechnology $\mathrm{GmbH}$, Erlangen, Germany) according to the manufacturer's instructions, and a DS-11 spectrophotometer (DeNovix, Wilmington, DE, USA) was used to measure the total concentration of RNA. Reverse transcription was performed using the Maxima ${ }^{\circledR}$ First Strand cDNA Synthesis Kit (Thermo Fisher Scientific, Inc., Waltham, MA, USA) and the samples were incubated into Tadvanced Biometra Product line (Analytik Jena AG, Göttingen, Germany) according to the following thermal program: $10 \mathrm{~min}$ at $25^{\circ} \mathrm{C}, 15 \mathrm{~min}$ at $50{ }^{\circ} \mathrm{C}$ and $5 \mathrm{~min}$ at $85^{\circ} \mathrm{C}$. The quantitative real-time PCR was conducted using a Quant Studio 5 real-time PCR system (Thermo Fisher Scientific, Inc., Waltham, MA, USA). The analysis was performed using $20 \mu \mathrm{L}$ reactions containing Power SYBR-Green PCR Master 
Mix (Thermo Fisher Scientific, Inc., Waltham, MA, USA), samples' cDNA, the sense and antisense primer and pure water. The following primer pairs were used (Table 2): $18 \mathrm{~S}$ and GAPDH (as housekeeping genes), Bax, Bcl-2 (Thermo Fisher Scientific, Inc., Waltham, MA, USA), Bid, Bad, Bak, Bcl-xL, caspase 3, caspase 8 and Apaf- 1 (Eurogentec, Seraing, Belgium). Normalized, relative expression data were calculated using the comparative threshold cycle $(2-\Delta \Delta \mathrm{Ct})$ method.

Table 2. The oligonucleotides of the primers used in the study.

\begin{tabular}{|c|c|c|}
\hline Primer's Name & Forward & Reverse \\
\hline $18 S^{*}$ & $5^{\prime}$ GTAACCCGTTGAACCCCATT $3^{\prime}$ & $5^{\prime}$ CCA-TCC-AAT-CGG-TAGTAG-CG $3^{\prime}$ \\
\hline$G A P D H^{*}$ & 5'AAG-GTG-AAG-GTC-GGA-GTC-AAC 3' & 5'GGG-GTC-ATT-GAT-GGC-AAC-AAT-A $3^{\prime}$ \\
\hline Bax & $5^{\prime}$ GCCGGGTTGTCGCCCTTTT 3' & $5^{\prime}$ CCGCTCCCGGAGGAAGTCCA $3^{\prime}$ \\
\hline Bid & 5'CCT-TGC-TCC-GTG-ATG-TCT-TTC 3' & 5'GTA-GGT-GCC-TAG-GTT-CTG-GT 3' \\
\hline Bad & $5^{\prime}$ CCC-AGA-GTT-TGA-GCC-GAG-TG $3^{\prime}$ & 5'CCC-ATC-CCT-TCG-TCC-T $3^{\prime}$ \\
\hline Bak & 5'ATGGTCACCTTACCTCTGCAA $3^{\prime}$ & 5'TCATAGCGTCGGTTGATGTCG 3' \\
\hline$B c l-2$ & $5^{\prime}$ CGGGAGATGTCGCCCCTGGT $3^{\prime}$ & $5^{\prime}$ GCATGCTGGGGCCGTACAGT 3' \\
\hline$B c l-X L$ & $5^{\prime}$ GATCCCCATGGCAGCAGTAAAGCAAG 3' & $5^{\prime}$ CCCCATCCCGGAAGAGTTCATTCACT $3^{\prime}$ \\
\hline Caspase 3 & 5'GCGGTTGTAGAAGAGTTTCGTG 3' & 5'CTCACGGCCTGGGATTTCAA 3' \\
\hline Caspase 8 & 5'AGAGTCTGTGCCCAAATCAAC 3' & 5'GCTGCTTCTCTCTTTGCTGAA $3^{\prime}$ \\
\hline Apaf-1 & 5'CACGTTCAAAGGTGGCTGAT $3^{\prime}$ & 5'TGGTCAACTGCAAGGACCAT $3^{\prime}$ \\
\hline
\end{tabular}

* housekeeping gene.

\subsection{Mitochondria Localization Using Immunofluorescence}

A375 cells $\left(1 \times 10^{6}\right.$ cells/well $)$ were seeded on a sterile slide in 6-well plates and stimulated with BA $(10 \mu \mathrm{M})$ for $24 \mathrm{~h}$. The staining protocol applied in the present study was based on a previous protocol [46] with several changes. Concisely, after the $24 \mathrm{~h}$ stimulation, the cells were washed three times with ice-cold PBS and fixed with paraformaldehyde $4 \%$ for $1 \mathrm{~h}$ at room temperature (RT). This step was followed by three times washing step with ice-cold PBS and permeabilization with a $2 \%$ Triton X/PBS solution for $30 \mathrm{~min}$ at RT. After washing with ice-cold PBS $/ 0.01 \%$ Triton X, cells were blocked with $30 \%$ FBS in $0.01 \%$ Triton $\mathrm{X}$ for $1 \mathrm{~h}$, followed by another washing step. To visualize the F-actin fibers, it was used Alexa Fluor ${ }^{\circledR} 555$ Phalloidin antibody (Cell Signaling Technology, Danvers, MA, USA) (incubation overnight at $4{ }^{\circ} \mathrm{C}$ using a 1:20 dilution). For the staining of COX IV-Mitochondrial marker it was used as primary antibody-Anti-COX IV antibody Mitochondrial marker (ab33985) (Abcam, Cambridge, United Kingdom) (incubation overnight at $4{ }^{\circ} \mathrm{C}$ using a 1:500 dilution), followed by the addition of the specific secondary antibodyDonkey Anti-Goat IgG H\&L (Alexa Fluor ${ }^{\circledR}$ 488-ab150129, Abcam, Cambridge, United Kingdom) next day for $2 \mathrm{~h}$ at room temperature and dark. The final step consisted of counterstaining the cells nuclei with 4',6-diamidino-2-phenylindol (DAPI) for $15 \mathrm{~min}$.

\subsection{Bioenergetic Profile of A375 Human Melanoma Cells}

A375 cells $\left(1.5 \times 10^{4}\right.$ cells/well $)$ were placed in XFe24 well culture plates and treated with increasing concentrations $(5,10$, and $50 \mu \mathrm{M})$ of BA or DMSO (the BA vehicle), respectively; several wells were left untreated as control group. Background correction wells (i.e., wells that were not seeded with cells) were included in the assay to normalize the data to background plate noise. Plates were further placed in an incubator at $37^{\circ} \mathrm{C}$ and $5 \% \mathrm{CO}_{2}$ atmosphere, allowing the cells to adhere for $24 \mathrm{~h}$. The analysis of the bioenergetic profile of A375 cells was performed in six in vitro experiments with the Seahorse XFe24 extracellular flux analyzer (Agilent Technologies, Inc., Santa Clara, CA, USA), an automatic platform that provides a simultaneous measurement of oxygen consumption rate (OCR) as the indicator of mitochondrial respiration and the extracellular acidification rate (ECAR) as the indirect measurement of anaerobic glycolysis according to a previously described method [64]. In brief, the metabolic activity of A375 cells was challenged with the classic modulators of the mitochondrial electron transport chain: the first automatic injection was 
performed with Oligomycin $(1 \mu \mathrm{g} / \mathrm{mL})$, the inhibitor of the mitochondrial ATP synthase; FCCP $(3 \mu \mathrm{M})$, the classic uncoupler was further injected, followed by Antimycin A $(5 \mu \mathrm{M})$, the inhibitor of mitochondrial complex III. OCR was reported in units of pmol $\mathrm{min}^{-1}$, while ECAR as $\mathrm{mpH} \mathrm{min}^{-1}$ was automatically converted to proton production rate (PPR) expressed as pmol $\mathrm{H}^{+} \mathrm{min}^{-1}$ using the determined buffer capacity of the media and the chamber volume in $\mathrm{XFe} 24$ Analyzer.

\subsection{High-Resolution Respirometry Studies in Permeabilized Cells}

Mitochondrial respiration was assessed in real time at $37{ }^{\circ} \mathrm{C}$ by means of highresolution respirometry (HRR) (Oxygraph-2k; Oroboros Instruments $\mathrm{GmbH}$, Innsbruck, Austria). Mitochondrial respiratory rates were obtained by following a SUIT protocol, adjusted to obtain both separate and conjunctive electron flow from complex I (CI) or/and complex II (CII). Prior to mitochondrial respiratory function assessment, the cells grown in T75 culture flasks were washed with PBS, trypsinized and resuspended in respiration medium $\left(3 \mathrm{mM} \mathrm{MgCl}_{2} \times 6 \mathrm{H}_{2} \mathrm{O}, 0.5 \mathrm{mM}\right.$ EGTA, $20 \mathrm{mM}$ taurine, $10 \mathrm{mM} \mathrm{KH}_{2} \mathrm{PO}_{4}, 60 \mathrm{mM}$ lactobionic acid, $110 \mathrm{mM}$ sucrose, $20 \mathrm{mM}$ HEPES, $1 \mathrm{~g} / \mathrm{L} \mathrm{BSA}, \mathrm{pH} 7.1,37^{\circ} \mathrm{C}$ ) at a cell density $\left(1 \times 10^{6} / \mathrm{mL}\right)$ that yielded a routine respiration of at least $20 \mathrm{pmol} / \mathrm{s} \mathrm{per} \mathrm{cm}^{3}$ volume-specific oxygen flux for the untreated (control) cells. A stock solution of BA (5 mM) in DMSO was prepared and used to yield a final constant concentration of BA of $10 \mu \mathrm{M}$ in the $2 \mathrm{~mL}$ chamber of the device. The concentration tested for DMSO was also $10 \mu \mathrm{M}$ and did not exceed $0.2 \%$. The titration of the substrates, inhibitors, and uncouplers was realized using Hamilton syringes (Hamilton Company, Reno, NV, USA).

In order to study the extended functional OXPHOS, by allowing the passage of externally added compounds into cytosol, cell membrane was permeabilized with digitonin (35 $\mu \mathrm{g} / 10^{6}$ cells). The optimal concentration used for a complete plasma membrane permeabilization was determined after a stepwise digitonin titration (data not shown), according to a protocol previously described by Pesta and Gnaiger [44]. The first respiratory rate recorded was routine respiration, obtained after the cells were suspended in a substratefree media, for 10-15 min. The SUIT protocol applied consisted of the following steps: (1) plasma membrane permeabilization with digitonin; (2) addition of glutamate (G: $10 \mathrm{mM}$ ) and malate (M: $5 \mathrm{mM})$, as mitochondrial CI substrates; (3) addition of ADP (5 mM) -active respiration dependent on CI; (4) addition of succinate (S: $10 \mathrm{mM}$ ), a CII substrate-induced the maximal OXPHOS capacity, driven by both CI and CII; (5) inhibition of ATP synthesis induced by oligomycin (1 $\mu \mathrm{g} / \mathrm{mL})$, an ATP synthase inhibitor; (6) successive titrations of FCCP $(1 \mu \mathrm{M} /$ step $)$, a classical uncoupling agent-the maximal respiratory capacity of the electron transport system (ETS); (7) addition of rotenone (0.5 $\mu \mathrm{M})$, a CI inhibitor, permitted the measurement of electron transport system dependent only on CII, and (8) addition of a complex CIII inhibitor, antimycin A $(2.5 \mu \mathrm{M})$, to completely inhibit the electron transport chain and to measure the residual oxygen consumption (ROX). All the respiratory rates obtained were corrected for ROX. Data were recorded using the DatLab software (Oroboros Instruments $\mathrm{GmbH}$, Innsbruck, Austria). For a better understanding and interpretation of mitochondrial respiration, the following parameters were analyzed:

1. Routine respiration (basal respiration) - $\mathrm{R}$ - represents the physiological respiratory activity in intact cells; is dependent of cellular energy need, energy turnover and the degree of coupling to phosphorylation to ADP [65]

2. State $2_{\mathrm{CI}}$ - Leak state- $\mathrm{L}$-basal respiration measured in the presence of malate (M) and glutamate $(\mathrm{G})$ — complex I dependent—substrates (NADH-generating substrates).

3. $\mathrm{OXPHOS}_{\mathrm{CI}}$ (active respiration) - $\mathrm{P}-$ mitochondrial respiratory capacity in the ADPactivated state of oxidative phosphorylation, measured after addition of ADP and in the presence of reducing complex I-dependent substrates: M and G.

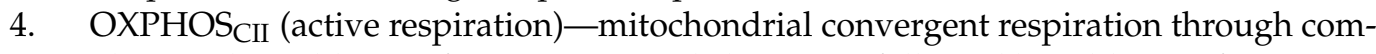
plex I and II; addition of ADP mentioned above was followed by addition of succinate (S), a complex II-dependent substrate $[65,66]$. 
5. State $4_{\mathrm{CI}+\mathrm{CII}}$ - Leak state-obtained after addition of oligomycin-an inhibitor of ATP synthase, this residual respiration rate is assigned to proton leak, yields a nonphosphorylating state and a return to basal respiration dependent on both $\mathrm{CI}$ and CII.

6. ETS $_{\mathrm{CI}+\mathrm{CII}}$ - the maximal respiratory capacity of the electron transport system mimics a physiological energy need inducing an increase of oxygen consumption. It is acquired after successive titrations of an uncoupler as FCCP (carbonyl cyanide p-(trifluoromethoxy) phenyl-hydrazone [67].

7. Residual oxygen consumption-ROX—indicates the remaining mitochondrial respiration after addition of rotenone - an inhibitor of complex I and antimycin—an inhibitor of complex III [67].

8. $\mathrm{R} / \mathrm{E}$ (Routine/ $\mathrm{ETS}_{\mathrm{CI}+\mathrm{II}}$ )—routine respiration normalized to ETS capacity; indicates how tight functions Routine respiration to the maximum capacity of the system.

9. L/E (State $4_{\mathrm{CI}+\mathrm{II}} / \mathrm{ETS}_{\mathrm{CI}+\mathrm{II}}$ )—Leak respiration normalized to ETS capacity; represents the part of maximum respiratory capacity linked to proton leak. Values as 0.0 indicate fully coupled mitochondria, whereas 1.0 is attributed to fully uncoupled mitochondria [44].

10. $\mathrm{RCR}-\left(\mathrm{OXPHOS}_{\mathrm{CI}+\mathrm{II}} /\right.$ State $\left.4_{\mathrm{CI}+\mathrm{II}}\right)$-respiratory control ratio is defined as the ratio between active respiration and leak state obtained after oligomycin addition; is strongly affected by any change in oxidative phosphorylation and is considered a useful indicator of mitochondrial dysfunction [35].

\subsection{Statistical Analysis}

The results obtained were expressed as means $\pm \mathrm{SD}$, and the difference between means was compared by one-way ANOVA, followed by Dunnett's multiple comparison post hoc test and unpaired $t$ test with Welch's correction (GraphPad Prism version 6.0.0 for Windows, GraphPad Software, San Diego, CA, USA, www.graphpad.com, accessed on 18 March 2021). The difference between groups was considered statistically significant if $p<0.05$ and are marked with ${ }^{*}\left({ }^{*} p<0.05,{ }^{* *} p<0.01,{ }^{* * *} p<0.001\right.$ and $\left.{ }^{* * * *} p<0.0001\right)$. Data were expressed as means \pm SEM. Data analysis used one-way ANOVA followed by a post-hoc Dunnett's multiple comparison test (GraphPad Prism version 5.0.0 for Windows, GraphPad Software, San Diego, CA, USA, www.graphpad.com, accessed on 18 March 2021). The difference was considered statistically significant if $p<0.05$.

\section{Conclusions}

Our results indicate that betulinic acid elicited a dose-dependent inhibitory effect on both mitochondrial respiration and glycolysis in A375 human melanoma cells. Mitochondrial bioenergetic dysfunction was associated with cytoskeleton reorganization (actin fibers), changes in mitochondrial morphology, a decrease of mitochondrial membrane potential and the upregulation of pro-apoptotic markers (Bax, Bad, and Bax). Taken together, these findings suggest that the molecular targeting of mitochondria bioenergetics with betulinic acid might represent a valid strategy for advanced melanoma and offer a novel perspective in understating the BA's antimelanoma mechanism of action.

Author Contributions: Conceptualization, D.C. and M.D.M.; Data curation, A.M., O.-M.A., I.M., G.A.D., C.P., C.S., M.B. and B.V.; Formal analysis, I.P., A.M., I.M., G.A.D. and B.V.; Funding acquisition, C.A.D. and C.S.; Investigation, D.C., A.M., O.-M.A., I.M., C.P. and M.B.; Methodology, D.C., A.M., O.-M.A., I.M. and M.B.; Project administration, D.C. and C.A.D.; Resources, C.S. and B.V.; Software, I.P., O.-M.A., G.A.D. and C.S.; Supervision, C.A.D. and M.D.M.; Validation, D.C., I.P., C.P. and M.D.M.; Visualization, G.A.D. and B.V.; Writing—original draft, D.C., C.P. and M.B.; Writing-review \& editing, C.A.D., I.P. and M.D.M. All authors have read and agreed to the published version of the manuscript.

Funding: This work was supported by a grant of the Romanian Ministry of Research and Innovation, CNCS-UEFISCDI, grant no PN-III-P1-1.1-PD-2016-1982, within PNCDI III, and partially funded by Romanian Ministry of Education and Research, CNCS-UEFISCDI, grant number PN-III-P1-1.1-TE2019-2134, within PNCDI III, acronym BAPRONIO. 
Acknowledgments: The experiments were conducted within the Research Center of PharmacoToxicological evaluations from the Faculty of Pharmacy and the Center for Translational Research and Systems Medicine from the Faculty of Medicine, "Victor Babes" University of Medicine and Pharmacy, Timisoara.

Conflicts of Interest: The authors declare no conflict of interest. The funders had no role in the design of the study; in the collection, analyses, or interpretation of data; in the writing of the manuscript, or in the decision to publish the results.

\section{References}

1. Prado, G.; Svoboda, R.M.; Rigel, D.S. What's New in Melanoma. Dermatol. Clin. 2019, 37, 159-168. [CrossRef] [PubMed]

2. Gajos-Michniewicz, A.; Czyz, M. Role of miRNAs in Melanoma Metastasis. Cancers 2019, 11, 326. [CrossRef]

3. Coricovac, D.; Dehelean, C.; Moaca, E.A.; Pinzaru, I.; Bratu, T.; Navolan, D.; Boruga, O. Cutaneous Melanoma-A Long Road from Experimental Models to Clinical Outcome: A Review. Int. J. Mol. Sci. 2018, 19, 1566. [CrossRef] [PubMed]

4. European Cancer Information System. ECIS. Available online: https:/ / ecis.jrc.ec.europa.eu/ (accessed on 25 February 2021).

5. Wróbel, S.; Przybyło, M.; Stępień, E. The Clinical Trial Landscape for Melanoma Therapies. J. Clin. Med. 2019, 8, 368. [CrossRef]

6. Hosseini, M.; Kasraian, Z.; Rezvani, H.R. Energy metabolism in skin cancers: A therapeutic perspective. Biochim. Biophys. Acta Bioenerg. 2017, 1858, 712-722. [CrossRef]

7. Srinivasan, S.; Guha, M.; Kashina, A.; Avadhani, N.G. Mitochondrial dysfunction and mitochondrial dynamics-The cancer connection. Biochim. Biophys. Acta Bioenerg. 2017, 1858, 602-614. [CrossRef] [PubMed]

8. Porporato, P.E.; Filigheddu, N.; Pedro, J.M.B.; Kroemer, G.; Galluzzi, L. Mitochondrial metabolism and cancer. Cell Res. 2018, 28, 265-280. [CrossRef] [PubMed]

9. Avagliano, A.; Fiume, G.; Pelagalli, A.; Sanità, G.; Ruocco, M.R.; Montagnani, S.; Arcucci, A. Metabolic Plasticity of Melanoma Cells and Their Crosstalk With Tumor Microenvironment. Front. Oncol. 2020, 10, 722. [CrossRef]

10. Lim, J.H.; Luo, C.; Vazquez, F.; Puigserver, P. Targeting mitochondrial oxidative metabolism in melanoma causes metabolic compensation through glucose and glutamine uti-lization. Cancer Res. 2014, 74, 3535-3545. [CrossRef] [PubMed]

11. Aminzadeh-Gohari, S.; Weber, D.D.; Catalano, L.; Feichtinger, R.G.; Kofler, B.; Lang, R. Targeting Mitochondria in Melanoma. Biomolecules 2020, 10, 1395. [CrossRef] [PubMed]

12. Viale, A.; Corti, D.; Draetta, G.F. Tumors and mitochondrial respiration: A neglected connection. Cancer Res. 2015, 75, 3685-3686. [CrossRef]

13. Theodosakis, N.; Micevic, G.; Kelly, D.P.; Bosenberg, M. Mitochondrial function in melanoma. Arch. Biochem. Biophys. 2014, 563, 56-59. [CrossRef]

14. Fulda, S. Betulinic acid for cancer treatment and prevention. Int. J. Mol. Sci. 2008, 9, 1096. [PubMed]

15. Ríos, J.L.; Máñez, S. New Pharmacological Opportunities for Betulinic Acid. Planta Med. 2018, 84, 8-19. [CrossRef] [PubMed]

16. Sorriento, D.; Pascale, A.V.; Finelli, R.; Carillo, A.L.; Annunziata, R.; Trimarco, B.; Iaccarino, G. Targeting mitochondria as therapeutic strategy for metabolic disorders. Sci. World J. 2014, 2014, 604685. [CrossRef] [PubMed]

17. Gheorgheosu, D.; Duicu, O.; Dehelean, C.; Soica, C.; Muntean, D. Betulinic acid as a potent and complex antitumor phytochemical: A minireview. Anticancer Agents Med. Chem. 2014, 14, 936.

18. Heiss, E.H.; Kramer, M.P.; Atanasov, A.G.; Beres, H.; Schachner, D.; Dirsch, V.M. Glycolytic switch in response to betulinic acid in non-cancer cells. PLoS ONE 2014, 9, e115683. [CrossRef]

19. Tan, Y.; Yu, R.; Pezzuto, J.M. Betulinic acid-induced programmed cell death in human melanoma cells involves mitogen-activated protein kinase activation. Clin. Cancer Res. 2003, 9, 2866.

20. Zuco, V.; Supino, R.; Righetti, S.C.; Cleris, L.; Marchesi, E.; Gambacorti-Passerini, C.; Formelli, F. Selective cytotoxicity of betulinic acid on tumor cell lines, but not on normal cells. Cancer Lett. 2002, 175, 17-25. [CrossRef] [PubMed]

21. Martins, W.K.; Gomide, A.B.; Costa, É.T.; Junqueira, H.C.; Stolf, B.S.; Itri, R.; Baptista, M.S. Membrane damage by betulinic acid provides insights into cellular aging. Biochim. Biophys. Acta Gen. Subj. 2017, 1861, 3129-3143. [CrossRef] [PubMed]

22. Surowiak, P.; Drag, M.; Materna, V.; Dietel, M.; Lage, H. Betulinic acid exhibits stronger cytotoxic activity on the normal melanocyte NHEM-neo cell line than on drug-resistant and drug-sensitive MeWo melanoma cell lines. Mol. Med. Rep. 2009, 2, 543-548. [CrossRef] [PubMed]

23. Nedopekina, D.A.; Gubaidullin, R.R.; Odinokov, V.N.; Maximchik, P.V.; Zhivotovsky, B.; Bel'skii, Y.P.; Khazanov, V.A.; Manuylova, A.V.; Gogvadze, V.; Spivak, A.Y. Mitochondria-targeted betulinic and ursolic acid derivatives: Synthesis and anticancer activity. MedChemComm 2017, 8, 1934-1945. [CrossRef] [PubMed]

24. Seca, A.M.L.; Pinto, D.C.G.A. Plant Secondary Metabolites as Anticancer Agents: Successes in Clinical Trials and Therapeutic Application. Int. J. Mol. Sci. 2018, 19, 263. [CrossRef]

25. Clinical trial-Evaluation of $20 \%$ Betulinic Acid Ointment for Treatment of Dysplastic Nevi (Moderate to Severe Dysplasia). Available online: https:/ / www.clinicaltrials.gov / ct2/ show / NCT00346502?term=betulinic+acid\&draw=2\&rank=1 (accessed on 20 January 2021).

26. Dehelean, C.A.; Marcovici, I.; Soica, C.; Mioc, M.; Coricovac, D.; Iurciuc, S.; Cretu, O.M.; Pinzaru, I. Plant-Derived Anticancer Compounds as New Perspectives in Drug Discovery and Alternative Therapy. Molecules 2021, 26, 1109. [CrossRef] 
27. Ramsay, E.E.; Hogg, P.J.; Dilda, P.J. Mitochondrial metabolism inhibitors for cancer therapy. Pharm. Res. 2011, $28,2731-2744$. [CrossRef]

28. Vazquez, F.; Lim, J.H.; Chim, H.; Bhalla, K.; Girnun, G.; Pierce, K.; Clish, C.B.; Granter, S.R.; Widlund, H.R.; Spiegelman, B.M.; et al. PGC1 $\alpha$ expression defines a subset of human melanoma tumors with increased mitochondrial capacity and resistance to oxidative stress. Cancer Cell 2013, 23, 287-301. [CrossRef]

29. Haq, R.; Shoag, J.; Andreu-Perez, P.; Yokoyama, S.; Edelman, H.; Rowe, G.C.; Frederick, D.T.; Hurley, A.D.; Nellore, A.; Kung, A.L.; et al. Oncogenic BRAF regulates oxidative metabolism via PGC1 $\alpha$ and MITF. Cancer Cell 2013, 23, 302-315. [CrossRef]

30. Arozarena, I.; Wellbrock, C. Overcoming resistance to BRAF inhibitors. Ann. Transl. Med. 2017, 5, 387. [CrossRef]

31. Gopal, Y.N.; Rizos, H.; Chen, G.; Deng, W.; Frederick, D.T.; Cooper, Z.A.; Scolyer, R.A.; Pupo, G.; Komurov, K.; Sehgal, V.; et al. Inhibition of mTORC1/2 overcomes resistance to MAPK pathway inhibitors mediated by PGC1 $\alpha$ and oxidative phosphorylation in melanoma. Cancer Res. 2014, 74, 7037-7047. [CrossRef] [PubMed]

32. Muntean, D.M.; Sturza, A.; Pavel, I.Z.; Duicu, O.M. Modulation of Cancer Metabolism by Phytochemicals-A Brief Overview. Anticancer Agents Med. Chem. 2018, 18, 684-692. [CrossRef]

33. Sturza, A.; Pavel, I.; Ancușa, S.; Danciu, C.; Dehelean, C.; Duicu, O.; Muntean, D. Quercetin exerts an inhibitory effect on cellular bioenergetics of the B164A5 murine melanoma cell line. Mol. Cell. Biochem. 2018, 447, 103-109. [CrossRef]

34. Wang, G.; Yu, Y.; Wang, Y.Z.; Zhu, Z.M.; Yin, P.H.; Xu, K. Effects and mechanisms of fatty acid metabolism-mediated glycolysis regulated by betulinic acid-loaded nanoliposomes in colorectal cancer. Oncol. Rep. 2020, 44, 2595-2609. [CrossRef] [PubMed]

35. Brand, M.D.; Nicholls, D.G. Assessing mitochondrial dysfunction in cells. Biochem. J. 2011, 435, 297-312. [CrossRef]

36. Weinberg, S.E.; Chandel, N.S. Targeting mitochondria metabolism for cancer therapy. Nat. Chem. Biol. 2015, 11, 9-15. [CrossRef]

37. Trotta, A.P.; Gelles, J.D.; Serasinghe, M.N.; Loi, P.; Arbiser, J.L.; Chipuk, J.E. Disruption of mitochondrial electron transport chain function potentiates the pro-apoptotic effects of MAPK inhibition. J. Biol. Chem. 2017, 292, 11727-11739. [CrossRef]

38. Rodríguez-Enríquez, S.; Pacheco-Velázquez, S.C.; Marín-Hernández, Á.; Gallardo-Pérez, J.C.; Robledo-Cadena, D.X.; HernándezReséndiz, I.; García-García, J.D.; Belmont-Díaz, J.; López-Marure, R.; Hernández-Esquivel, L.; et al. Resveratrol inhibits cancer cell proliferation by impairing oxidative phosphorylation and inducing oxidative stress. Toxicol. Appl. Pharmacol. 2019, $370,65-77$. [CrossRef] [PubMed]

39. Sundstrøm, T.; Prestegarden, L.; Azuaje, F.; Aasen, S.N.; Røsland, G.V.; Varughese, J.K.; Bahador, M.; Bernatz, S.; Braun, Y.; Harter, P.N.; et al. Inhibition of mitochondrial respiration prevents BRAF-mutant melanoma brain metastasis. Acta Neuropathol. Commun. 2019, 7, 55. [CrossRef] [PubMed]

40. Baffy, G. Mitochondrial uncoupling in cancer cells: Liabilities and opportunities. Biochim. Biophys. Acta Bioenerg. 2017, 1858, 655-664. [CrossRef]

41. Brennan, J.P.; Southworth, R.; Medina, R.A.; Davidson, S.M.; Duchen, M.R.; Shattock, M.J. Mitochondrial uncoupling, with low concentration FCCP, induces ROS-dependent cardioprotection independent of KATP channel activation. Cardiovasc. Res. 2006, 72, 313-321. [CrossRef]

42. Lim, H.W.; Lim, H.Y.; Wong, K.P. Uncoupling of oxidative phosphorylation by curcumin: Implication of its cellular mechanism of action. Biochem. Biophys. Res. Commun. 2009, 389, 187. [CrossRef]

43. Terada, H. Uncouplers of oxidative phosphorylation. Environ. Health Perspect. 1990, 87, 213-218. [CrossRef] [PubMed]

44. Pesta, D.; Gnaiger, E. High-resolution respirometry: OXPHOS protocols for human cells and permeabilized fibers from small biopsies of human muscle. Methods Mol. Biol. 2012, 810, 25. [PubMed]

45. Liebscher, G.; Vanchangiri, K.; Mueller, T.; Feige, K.; Cavalleri, J.M.; Paschke, R. In vitro anticancer activity of Betulinic acid and derivatives thereof on equine melanoma cell lines from grey horses and in vivo safety assessment of the compound NVX-207 in two horses. Chem. Biol. Interact. 2016, 246, 20-29. [CrossRef]

46. Gheorgheosu, D.; Jung, M.; Ören, B.; Schmid, T.; Dehelean, C.; Muntean, D.; Brüne, B. Betulinic acid suppresses NGAL-induced epithelial-to-mesenchymal transition in melanoma. Biol. Chem. 2013, 394, 773-781. [CrossRef]

47. Pisha, E.; Chai, H.; Lee, I.S.; Chagwedera, T.E.; Farnsworth, N.R.; Cordell, G.A.; Beecher, C.W.; Fong, H.H.; Kinghorn, A.D.; Brown, D.M.; et al. Discovery of betulinic acid as a selective inhibitor of human melanoma that functions by induction of apoptosis. Nat. Med. 1995, 1, 1046-1051. [CrossRef]

48. Fulda, S.; Scaffidi, G.; Susin, S.A.; Krammer, P.H.; Kroemer, G.; Peter, M.E.; Debatin, K.M. Activation of mitochondria and release of mitochondrial apoptogenic factors by betulinic acid. J. Biol. Chem. 1998, 273, 33942-33948. [CrossRef] [PubMed]

49. Anvekar, R.A.; Asciolla, J.J.; Missert, D.J.; Chipuk, J.E. Born to be alive: A role for the BCL-2 family in melanoma tumor cell survival, apoptosis, and treatment. Front. Oncol. 2011, 1, 34. [CrossRef]

50. Brunelle, J.K.; Letai, A. Control of mitochondrial apoptosis by the Bcl-2 family. J. Cell Sci. 2009, 122, 437-441. [CrossRef] [PubMed]

51. Frederick, D.T.; Fragomeni, R.A.S.; Schalck, A.; Ferreiro-Neira, I.; Hoff, T.; Cooper, Z.A.; Haq, R.; Panka, D.J.; Kwong, L.N.; Davies, M.A.; et al. Clinical profiling of BCL-2 family members in the setting of BRAF inhibition offers a rationale for targeting de novo resistance using BH3 mimetics. PLoS ONE 2014, 9, e101286. [CrossRef]

52. Kumar, P.; Bhadauria, A.S.; Singh, A.K.; Saha, S. Betulinic acid as apoptosis activator: Molecular mechanisms, mathematical modeling and chemical modifications. Life Sci. 2018, 209, 24-33. [CrossRef]

53. Pandey, M.K.; Sung, B.; Aggarwal, B.B. Betulinic acid suppresses STAT3 activation pathway through induction of protein tyrosine phosphatase SHP-1 in human multiple myeloma cells. Int. J. Cancer 2010, 127, 282-292. [CrossRef] 
54. Xu, T.; Pang, Q.; Wang, Y.; Yan, X. Betulinic acid induces apoptosis by regulating PI3K/Akt signaling and mitochondrial pathways in human cervical cancer cells. Int. J. Mol. Med. 2017, 40, 1669-1678. [CrossRef]

55. Wick, W.; Grimmel, C.; Wagenknecht, B.; Dichgans, J.; Weller, M. Betulinic acid-induced apoptosis in glioma cells: A sequential requirement for new protein synthesis, for-mation of reactive oxygen species, and caspase processing. J. Pharmacol. Exp. Ther. 1999, 289, 1306-1312.

56. Fulda, S.; Friesen, C.; Los, M.; Scaffidi, C.; Mier, W.; Benedict, M.; Nuñez, G.; Krammer, P.H.; Peter, M.E.; Debatin, K.M. Betulinic acid triggers CD95 (APO-1/Fas)- and p53-independent apoptosis via activation of caspases in neuroectodermal tumors. Cancer Res. 1997, 57, 4956-4964. [PubMed]

57. Thurnher, D.; Turhani, D.; Pelzmann, M.; Wannemacher, B.; Knerer, B.; Formanek, M.; Wacheck, V.; Selzer, E. Betulinic acid: A new cytotoxic com-pound against malignant head and neck cancer cells. Head Neck 2003, 25, 732-740. [CrossRef] [PubMed]

58. Selzer, E.; Thallinger, C.; Hoeller, C.; Oberkleiner, P.; Wacheck, V.; Pehamberger, H.; Jansen, B. Betulinic acid-induced Mcl-1 expression in human melanoma-mode of action and functional significance. Mol. Med. 2002, 8, 877-884. [CrossRef]

59. Farcas, C.G.; Macasoi, I.; Pinzaru, I.; Chirita, M.; Mihaila, M.C.C.; Dehelean, C.; Avram, S.; Loghin, F.; Mocanu, L.; Rotaru, V.; et al. Controlled Synthesis and Characterization of Micrometric Single Crystalline Magnetite With Superparamagnetic Behavior and Cytocompatibility/Cytotoxicity Assessments. Front. Pharmacol. 2020, 11, 410. [CrossRef] [PubMed]

60. Maghiari, A.L.; Coricovac, D.; Pinzaru, I.A.; Macașoi, I.G.; Marcovici, I.; Simu, S.; Navolan, D.; Dehelean, C. High Concentrations of Aspartame Induce Pro-Angiogenic Effects in Ovo and Cytotoxic Effects in HT-29 Human Colorectal Carcinoma Cells. Nutrients 2020, 12, 3600. [CrossRef]

61. Farcas, C.G.; Dehelean, C.; Pinzaru, I.A.; Mioc, M.; Socoliuc, V.; Moaca, E.A.; Avram, S.; Ghiulai, R.; Coricovac, D.; Pavel, I.; et al. Thermosensitive Betulinic Acid-Loaded Magnetoliposomes: A Promising Antitumor Potential for Highly Aggressive Human Breast Adenocarcinoma Cells Under Hyperthermic Conditions. Int. J. Nanomed. 2020, 15, 8175-8200. [CrossRef] [PubMed]

62. Pinzaru, I.; Tanase, A.; Enatescu, V.; Coricovac, D.; Bociort, F.; Marcovici, I.; Watz, C.; Vlaia, L.; Soica, C.; Dehelean, C. Proniosomal Gel for Topical Delivery of Rutin: Preparation, Physicochemical Characterization and In Vitro Toxicological Profile Using 3D Reconstructed Human Epidermis Tissue and 2D Cells. Antioxidants 2021, 10, 85. [CrossRef]

63. Sivandzade, F.; Bhalerao, A.; Cucullo, L. Analysis of the Mitochondrial Membrane Potential Using the Cationic JC-1 Dye as a Sensitive Fluorescent Probe. Bio. Protoc. 2019, 9, e3128. [CrossRef]

64. Duicu, O.M.; Scurtu, I.; Popescu, R.; Sturza, A.; Coricovac, D.; Danila, D.M.; Privistirescu, A.; Muntean, D.M. Assessment of the effects of methylene blue on cellular bioenergetics in H9c2 cells. Rev. Chim. 2015, 66, 519-522.

65. Makrecka-Kuka, M.; Krumschnabel, G.; Gnaiger, E. High-Resolution Respirometry for Simultaneous Measurement of Oxygen and Hydrogen Peroxide Fluxes in Permeabilized Cells, Tissue Homogenate and Isolated Mitochondria. Biomolecules 2015, 5, 1319-1338. [CrossRef] [PubMed]

66. Hals, I.K.; Bruerberg, S.G.; Ma, Z.; Scholz, H.; Björklund, A.; Grill, V. Mitochondrial Respiration in Insulin-Producing $\beta$-Cells: General Characteristics and Adaptive Effects of Hypoxia. PLoS ONE 2015, 10, e0138558. [CrossRef] [PubMed]

67. Jang, D.H.; Greenwood, J.C.; Spyres, M.B.; Eckmann, D.M. Measurement of Mitochondrial Respiration and Motility in Acute Care: Sepsis, Trauma, and Poisoning. J. Intensive Care Med. 2017, 32, 86. [CrossRef] [PubMed] 